\title{
WOUND DRESSINGS AS GROWTH FACTOR DELIVERY PLATFORMS FOR CHRONIC WOUND HEALING
}




\begin{abstract}
Introduction: Years of tissue engineering research have clearly demonstrated the potential of integrating growth factors (GFs) into scaffolds for tissue regeneration, a concept that has recently been applied to wound dressings. The old concept of wound dressings that only take a passive role in wound healing has now been overtaken, and advanced dressings which can take an active part in wound healing, are of current research interest.

Areas covered: In this review we will focus on the recent strategies for the delivery of GFs to wound sites with an emphasis on the different approaches used to achieve fine tuning over spatial and temporal concentrations to achieve therapeutic efficacy.

Expert Opinion: The use of GFs to accelerate wound healing and reduce scar formation is now considered a feasible therapeutic approach in patients with a high risk of infections and complications. The integration of micro- and nanotechnologies into wound dressings could be the key to overcome the inherent instability of GFs and offer adequate control over the release rate. Many investigations have led to encouraging outcomes in various in vitro and in vivo wound models, and it is expected that some of these technologies will satisfy clinical needs and will enter commercialization.
\end{abstract}

\title{
KEYWORDS
}

Wound healing; Growth factors; Wound dressing; Drug delivery; Nanotechnologies; Chronic wound. 


\section{INTRODUCTION}

\subsection{Overview}

As the outermost barrier of the body, the skin is the organ most challenged by a range of external stress factors (physical, chemical, thermal or radiation), resulting in frequent tissue damage. Every animal species can regenerate their tissue after injury, but not all organisms regenerate in the same way. Fish and amphibians, such as zebrafish and salamanders, can perfectly regenerate complex tissues without scar formation, and this happens even in cases of extensive damage such as the loss of their limbs ${ }^{1}$. Higher animals, such as mammals, are generally incapable of complete tissue regeneration and have developed a complex response to injury, which is characterized by four stages (i.e., hemostasis, inflammation, proliferation, and remodeling) to restore the integrity of damaged tissue $^{2}$. In humans, perfect tissue regeneration has only been described in fetal skin $^{3}$. In adult however, tissue repair commences immediately following tissue injury and, with few exceptions, results in the formation of an acellular fibrotic matrix (i.e., scar tissue) ${ }^{4}$. The replacement of functional tissue with fibrous connective tissue leads to a loss of original tissue structure and function, which alters the microarchitecture of the whole organ, eventually resulting in failure ${ }^{5,6}$. Fibrosis is a major pathological feature of many chronic diseases, and it has been estimated that it is associated with $45 \%$ of non-accident related casualties in the USA?

The wound healing process after skin injury involves a complex cascade of cellular and biochemical events between the different cellular constituents of the skin and its extracellular matrix (ECM). If this normal repair response is interrupted for some reason, two major outcomes can occur: i) an ulcerative skin defect (chronic wound) and ii) an excessive formation of scar (hypertrophic scar or keloid). Despite the enormous impact of chronic wounds and fibrosis on human health, there are currently no effective treatments to counteract these pathological challenges. The cellular and molecular mechanisms that underpin tissue repair and its failure to heal are still poorly understood, and this has affected the development of new treatments. Exogenous therapeutic biological molecules, such as growth factors (GFs), have great potential, however, inherent difficulties in reaching therapeutic concentrations at the wound site and effectively targeting the interconnected and complex signal pathways that drive the wound healing process are major clinical challenges. As the new generation of products, bioactive dressings made of materials which play an active role in the healing process and can also deliver incorporated GFs represent the new frontier in wound repair.

This review aims to discuss the most recent advances in the design, characterization, and evaluation of innovative wound dressings loaded with GFs. Many papers have been published over the years, confirming the potential of exogenous application of GFs in wound healing, but very few of them focused on integrating GFs into 3D constructs for wound dressings. After a brief overview of the role of GFs in the wound healing process, we will discuss the various strategies for integrating GFs into wound dressings and summarize the different approaches for their direct delivery to wound sites. Specific examples of such delivery systems and how they can be used to accelerate the healing of chronic wounds and 
reduce scar formation in the process are also reported.

\section{The complexity of the wound healing process}

As explained in-depth in many reviews published so far, the wound healing process consists of a series of carefully and precisely regulated steps and events that are initiated immediately after injury. The purpose of these events is not only to restore the skin barrier and homeostasis functions, but also to reduce the risk of infection and further complications $s^{4,5,8,9}$. Despite being a continuous event, wound healing can be divided into different phases to help understand the physiological processes taking place in the wound bed and the surrounding tissue $^{5}$. In adults and healthy humans, wound healing can be divided into a sequence of four time-dependent phases: hemostasis, inflammation, proliferation, and remodeling (Fig. 1). Each of these sequential, overlapping, and precisely programmed phases involves coordinated interactions between diverse immunological and biological systems, and any interruption or deregulation of one or more steps of the wound-healing process leads to nonhealing (chronic) wounds. Platelets, neutrophils, monocytes/macrophages, fibroblasts, lymphocytes, granulation tissue cells, and epidermal cells are among the cells that make their appearance in the wound bed. These cells release a series of biological macromolecules, such as GFs, cytokines, chemokines, antibodies, proteases, lipids, carbohydrates, collagen and nucleic acids ${ }^{10}$. The development of molecular biology and biotechnology has helped us better understand the role of these biological molecules during the distinct phases of the healing process, prompting interest in the use of exogenous biological molecules as therapies for skin wound healing.

As previously discussed, wound healing is a highly efficient process in which, multiple physiological factors contribute to wound resolution. In healthy individuals, the resolution of acute wounds (which are typically traumatic or surgical in origin) goes through the normal stages of wound healing and results in a time-dependent but predictable and orderly pattern of tissue repair ${ }^{11}$. However, such a complex response can easily give rise to abnormal alterations (generally due to underlying pathological conditions), resulting in insufficient healing rate (chronic wounds) and/or excessive healing (formation of scar tissue). Impaired production of GFs, insufficient keratinocyte and fibroblast migration and proliferation, abnormal granulation tissue and collagen accumulation, inadequate angiogenic response and impaired balance between the accumulation of ECM components and their remodeling by matrix metalloproteinases (MMPs) are just some of the known deficiencies in pathologic wound healing ${ }^{4-6,9}$. 

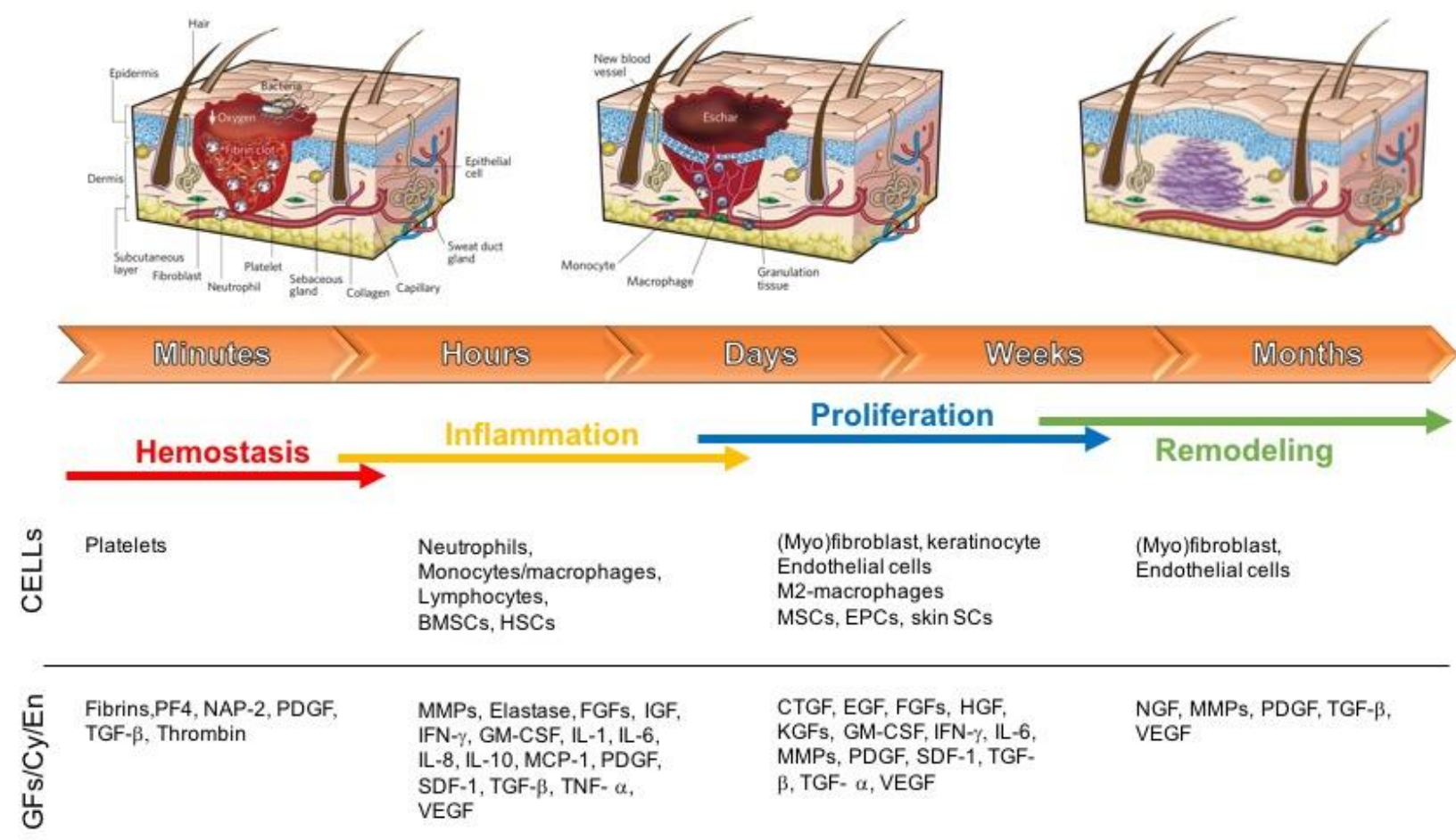

Figure 1: Schematic representation of the timeline of inflammatory cells, cytokines/GFs and proteinases, in different phases of spontaneous wound healing (reproduced from Catanzano and Boateng ${ }^{12}$ with permission from John Wiley and Sons). Abbreviations: CTGF: connective tissue growth factor; EGF: epidermal growth factor; FGF: fibroblast growth factor; GM-CSF: granulocyte-macrophage colony-stimulating factor; IGF: insulin growth factor; IFN: interferon; IL: interleukin; KGF: keratinocyte growth factor; VEGF: vascular endothelial growth factor; NGF: nerve growth factor; PDGF: platelet-derived growth factors; SDF: stromal cell-derived factor; TGF: transforming growth factor; TNF: tumor necrosis factor; Gm/Cy/En: growth factors/cytokines/enzymes; MMP: matrix metalloproteinase; SC: stem cell; BMSC: bone marrow SC, HSC, hematopoietic SC; EPC: endothelial progenitor cells; MSC: mesenchymal SC.

A chronic wound occurs when there is an inability to proceed through an orderly and timely reparative process to restore the anatomic and functional integrity of the injured site $^{13}$. Chronic wounds can be mainly classified into vascular ulcers (e.g., venous and arterial ulcers), pressure ulcers, and diabetic ulcers. Almost all chronic wounds can generally be assigned to one of these three clinical categories depending on the underlying cause. Vascular ulcers are frequently $(>70 \%)$ due to venous deficiencies caused by a sustained level of high blood pressure in the lower leg due to inadequate venous return. Other underlying causes of leg ulcers include arterial disease (reduced arterial blood supply to the lower $\operatorname{limb}$ ), vasculitis and skin malignancies. Pressure ulcers (PUs), also known as decubitus ulcers or bed sores, often occur in hospitalized or bedridden patients and are caused by a combination of persistent direct pressure and/or shear/friction forces over a bony prominence that obstructs blood flow to the tissue. Diabetic foot ulcers (DFUs) are a complication that has been estimated to occur in 15 to $25 \%$ people with diabetes and are caused by neural and vascular complications ${ }^{14}$.

Despite differences in etiology, a persistent inflammation state is a crucial feature common to all chronic (non-healing) wounds. Repeated tissue injury, the existence of persistent infection (particularly in the form of biofilms), local concentrations of GFs and ECM fragment molecules higher than normal, stimulate the excessive recruitment of 
inflammatory cells to the wound bed, and traps the wound in a chronic inflammatory state which fails to progress ${ }^{5,15}$. Compared to acute wounds, the levels of pro-inflammatory cytokines IL-1, IL-6, and TNF- $\alpha$ in chronic wounds are higher ${ }^{16,17}$. Conversely, the decrease in tissue inhibitors of MMPs leads to faster degradation of GFs and their receptors and destruction of ECM. The proteolytic destruction of ECM not only prevents the wound from moving forward into the proliferative phase, but also attracts more inflammatory cells, thus amplifying the inflammation cycle (Fig. 2) ${ }^{18,19}$. Moreover, phenotypic abnormalities in the epidermis- and dermis-derived cells, such as the lower density of GF receptors and reduced mitogenic potential, have been found on cells derived from chronic wounds ${ }^{20-23}$. These abnormalities prevent the resident cells from responding properly to wound healing signals $^{24}$.

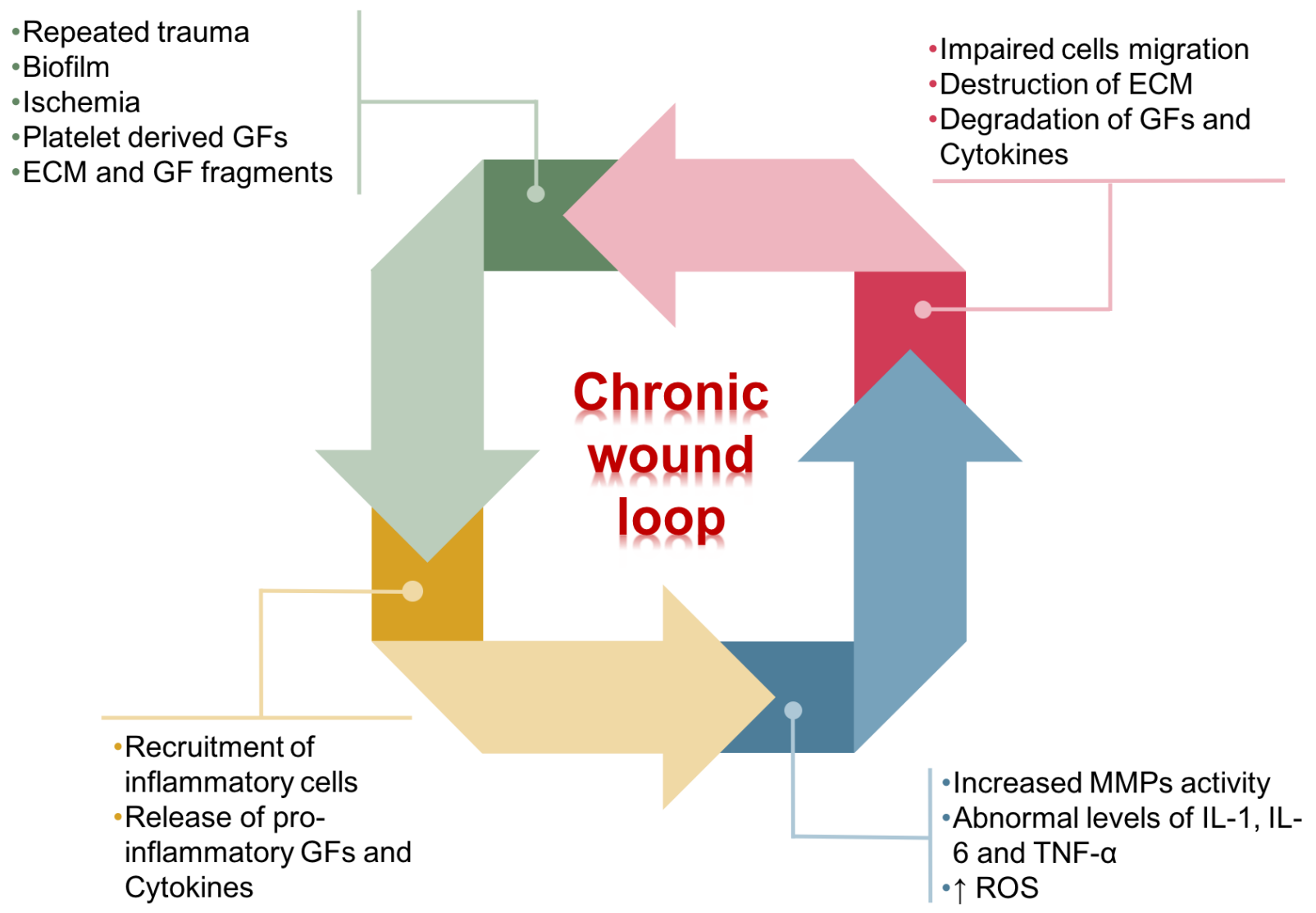

Figure 2. Representation of the deleterious cycles of inflammation, which contribute to wound chronicity. Persistent inflammation can be considered the hallmark of chronic (non-healing) wounds. The repeated tissue injury, the presence of microorganisms (e.g., biofilms), and the release of PDGFs stimulate the constant recruitment of inflammatory cells into the wound bed. These cells release pro-inflammatory cytokines (e.g., IL$1 \beta$ and TNF $\alpha$ ), leading to elevated levels of reactive oxygen species (ROS) and proteases (e.g., MMPs). High levels of ROS, together with increased activity of MMPs, result in the destruction of ECM components and the degradation of GFs. The proteolytic destruction of ECM further, attracts more inflammatory cells to the wound, thus turning the inflammation into a repeated detrimental and vicious cycle, which contribute to wound chronicity.

The alteration of the GFs that regulate cell proliferation and ECM production also profoundly impacts the progression or regression of scar formation. Excessive healing is 
manifested in humans as a keloid or a hypertrophic scar, characterized by overproduction of ECM and hyperproliferation of fibroblasts ${ }^{25,26}$. The pathogenesis of these scars is closely connected to delayed wound healing because of a prolonged inflammatory phase caused by chronic inflammation or infection. Several studies have proven that the risk of developing into hypertrophic scar is higher for wounds that take more than three weeks to heal ${ }^{27,28}$. This persistent inflammatory response often leads to increased vessel and cell numbers as well as excessive collagen deposition ${ }^{29}$. It is precisely these mediators of continuous inflammation that have an essential role in excessive healing. Cytokines such as IL-1, TNF$\alpha$, IL-6, SDF1 (also known as CXCL12), and IL-10, as well as GFs such as TGF- $\beta$, CTGF, PDGF, and bFGF, have a profound impact on the progression or regression of scar formation ${ }^{29-31}$. They execute and modulate a complex signaling network and when altered, could lead to hypervascularity and excessive (pathological) deposition of ECM components. Fibroblasts and myofibroblasts are the main cell types involved in scar pathogenesis ${ }^{30,} 32$. However, other cells, such as keratinocytes and mast cells, actively participate in the progression or regression of scars, resulting in the production of massive amounts of collagen, which favours the accumulation of ECM below the dermis, leading to scar formation ${ }^{32-34}$. The growing evidence of GF involvement in scar formation is opening new avenues for the development of innovative therapeutic approaches for the prevention and treatment of pathological scars. Local delivery of GFs, for example, could be used as an adjuvant to surgery or radiotherapy, an approach which is already considered more effective than surgical or pharmacological therapy on their $\mathrm{own}^{32}$.

\subsection{Critical aspects in the use of GFs in wound healing}

To correctly treat chronic wounds, it is essential to directly target the underlying systemic and metabolic disorders, such as infection or vascular insufficiency, which are responsible for the onset of the deleterious cycle of inflammation resulting in repeated and prolonged tissue insults. There has been an evolution of the concept of wound treatment (traditionally based only on debridement and infection prevention strategies), with the introduction of biological therapies. Therapeutic biological molecules represent the cuttingedge of biomedical research. Their use in wound healing is currently emerging as an effective way to enhance wound closure in difficult-to-heal wounds, by restoring the optimal microenvironment required for correct wound healing progression ${ }^{4,10,35-37}$. Their ability to perform complex functions by interacting with other biomolecules, coupled with reduced risk of side effects and low immunogenicity, provide inherent advantages for biological drugs over small molecule drugs ${ }^{38}$. Besides, they can be easily manufactured by biotechnological processes using cell bioreactors.

The impact of exogenous GFs on the wound microenvironment is significant even at low concentrations, leading to rapid increases in cell migration, proliferation, and differentiation ${ }^{39}$. It is now well established that deficiency in GFs is one of the critical factors that contributes to the development of chronic wounds ${ }^{40-43}$. Therefore, exogenous GFs can potentially be used in wound therapy to accelerate chronic wound healing and reduce scar 
formation. The rationale behind their use is based on the principle of replacing critically deficient components which support the standard wound healing process. GF deficiencies, including reduced levels of bFGF, PDGF, VEGF, and TGF- $\beta$, have been reported in chronic PUs when compared with acute wounds, suggesting that GF deficiencies are responsible for wound chronicity ${ }^{39,44}$. The introduction of modern biotechnology techniques, which made it possible to produce large quantities of chemically pure GFs at relatively low costs, has revolutionized the treatment of difficult to heal wounds. This notwithstanding, new challenges have emerged for pharmaceutical scientists. The chemical and physical instability and the reduced tissue/cell transport require the development of effective strategies for delivery of GFs to the target site. Moreover, it is worth emphasizing that these molecules tend to be heat-sensitive and susceptible to microbial contamination, which necessitates the implementation of aseptic principles during manufacturing.

Wound treatment using exogenous GFs could have significant beneficial effects, however, certain essential requirements must be satisfied. Firstly, GFs used in wound therapy act on the body's own ECM cells, therefore their pharmacological activity relies on the ability of these cells to respond to the exogenous GF stimuli. For this reason, only wounds that can synthesize a functional ECM could achieve optimal benefit from this application ${ }^{45}$. Secondly, the therapeutic response to exogenous GFs is strictly dependent on their spatial and temporal distribution within the wound ${ }^{46}$. The treatment of wounds with exogenous GFs is often ineffective since GFs rapidly diffuse from the administration site and are readily digested or deactivated by enzymes such as proteases in the wound area ${ }^{47}$. The low permeation of GFs through the outermost skin layer surrounding the lesion is another factor that limits the success of topical administration of exogenous GFs in wound therapy. Furthermore, their rapid elimination by exudation from the wound bed significantly reduces the efficacy of GFs following topical application ${ }^{39}$. Consequently, high doses and/or repeated administration over a long period are required to support and sustain tissue regeneration, leading to supra-physiological exposure to GFs which can lead to serious side effects (including oncogenesis), as well as greatly increasing the total cost of the therapy.

The systemic infusion of GFs into the vascular circulation generally results in their reduced accumulation in the target tissue and fast degradation in the blood compartment. Moreover, in chronic wounds and severe burns, the destruction of the surface blood vessels results in insufficient blood supply, requiring high doses of systemically administered drugs to achieve local therapeutic effects ${ }^{10}$. As previously discussed, a critical feature of chronic wounds is the generation of a proteolytic environment, due to the persistent inflammatory state caused by inflammatory cells infiltrating the wound site and prolonged up-regulation of pro-inflammatory cytokines and chemokines. This proteolytic environment enhances the degradation and sequestration of the locally produced GFs and cytokines, thus inhibiting their physiological functions and further slowing normal wound healing progression ${ }^{41}$. Significant deficiencies in GFs, including reduced levels of bFGF, PDGF, EGF, and TGF- $\beta$, have been reported in PUs compared with acute wounds ${ }^{48}$. In particular, PDGF expression is shown to be lower in chronic dermal ulcers than in acute surgical wounds ${ }^{44}$. 


\subsection{Topical administration of GFs}

Due to the large exposed surface area of the wound, the local application of GFs to the wound site in the form of intralesional injection or topical application is accepted as a standard delivery approach, even if various technological and biological challenges strongly limit its clinical relevance. For example, hypodermic injection of aqueous solutions of GFs, often result in an elevated concentration of the drugs outside of the therapeutic window, causing unwanted side effects and reducing therapeutic efficacy. Moreover, injections are quite unfavorable as they are painful and require professional assistance. The selection of a suitable area of delivery is another factor that affects the outcome of topical application of GFs. Chronic wounds are usually covered with a layer of non-viable tissue filled with proinflammatory cytokines and MMPs that must be crossed to reach the target cells. Therefore, if not adequately protected, a significant fraction of the active molecules may get deactivated before reaching the target. Besides, the significant exudate production in chronic wounds can dilute and further reduce the rate of penetration of topically administered GFs.

As already mentioned, the local injection of GFs in chronic wounds is a straightforward way to deliver these molecules to compensate for their deficiency in chronic wounds. Subcutaneous injection of recombinant human GM-CFS (rh-GM-CFS) ${ }^{49}$ and EGF ${ }^{50}$ into the wound base and contours have proved useful to increase vascularization, granulation tissue growth, and wound closure. However, the need for continuous injection by highly trained staff and the intrinsic disadvantage of this administration route (local irritation and pain, difficulty in controlling the rate of absorption, frequent change of the injection site) make this approach challenging to use in clinical practice.

Topical administration of GFs loaded in creams, gels, or ointments is another delivery option widely explored to promote wound healing ${ }^{51}$. Products containing some GFs such as PDGF, EGF, and bFGF are already approved for human use, and they are available on the market as preparations for external application onto wounds (Table 1). The formulation of GFs in a topical delivery system facilitates their therapeutic application in the clinical management of non-healing wounds such as DFUs, by providing a continuous exposure of residual epidermal cells to GFs that can significantly increase the wound healing rate ${ }^{52}$. For example, several randomized clinical trials have shown the ability of Becaplermin (brand name Regranex ${ }^{\circledR} \mathrm{Gel}$ ), which contains recombinant PDGF, to accelerate wound closure in DFUs and significantly reduce amputations ${ }^{53-56}$. Moreover, pharmacoeconomic studies have reinforced the cost-effectiveness of Becaplermin as an adjunct to proper wound care even if the treatment with this topical gel is expensive and requires frequent dressing changes. Topical formulations of GFs are indicated for external post-traumatic injury, postoperative surgical wounds, burns, venous ulcers, PUs, and DFUs that are recalcitrant to traditional interventions. Clinical evidence showed that topical formulations loaded with GFs could also be used for the enhancement of skin grafts ${ }^{57}$.

It is important to emphasize that topical therapy with GFs must always be used along with other standard procedures of chronic wound management, including debridement, infection control, pressure off-loading, and revascularization. Without adhering to these essential principles, the administration of an active substance is unlikely to result in improved healing. Moreover, an increased risk of malignancy is assumed with these treatments. A 20month follow-up study from two randomized controlled trials revealed an increased cancer 
risk compared with the control group for patients who had been treated with more than three tubes of Becaplermin ${ }^{54,58}$. However, the higher prevalence of cancer among diabetic patients makes these studies difficult to interpret, and further research is needed to provide a better understanding of the risks of these treatments.

Table 1 Topical products containing GFs approved for human use and currently available on the market ${ }^{12}$. Reproduced with permission from John Wiley and Sons.

\begin{tabular}{|c|c|c|c|c|c|}
\hline $\begin{array}{l}\text { Growth } \\
\text { factor }\end{array}$ & $\begin{array}{c}\text { International } \\
\text { nonproprietary } \\
\text { name (INN) }\end{array}$ & Brand name & Company & Formulation & Ref. \\
\hline PDGF & Becaplermin & Regranex ${ }^{\circledR}$ & Smith \& Nephew & Topical gel & 53,56 \\
\hline bFGF & Trafermin & Fiblast $^{\circledR}$ & $\begin{array}{l}\text { Kaken } \\
\text { Pharmaceutical } \\
\text { Co. }\end{array}$ & Spray solution & 59,60 \\
\hline EGF & Nepidermin & Heberprot-P $\mathrm{P}^{\circledR}$ & $\begin{array}{l}\text { Heber Biotec } \\
\text { S.A. }\end{array}$ & $\begin{array}{l}\text { Lyophilized } \\
\text { powder }\end{array}$ & 57 \\
\hline EGF & Nepidermin & Easyef ${ }^{\circledR}$ & $\begin{array}{l}\text { Daewoong } \\
\text { Pharmaceutical } \\
\text { Co., Ltd. }\end{array}$ & $\begin{array}{l}\text { Spray solution } \\
\text { or ointment }\end{array}$ & 61 \\
\hline EGF & Nepidermin & Regen-D 60/150 & $\begin{array}{l}\text { Bharat Biotech } \\
\text { International Ltd. }\end{array}$ & Topical gel & 62 \\
\hline
\end{tabular}

bFGF, basic fibroblast growth factor; EGF, epidermal growth factor; PDGF, platelet-derived growth factor.

Often, topical formulations are not effective enough for delivery of GFs to chronic wounds because creams and gels can rapidly absorb fluids, lose their rheological characteristics (become mobile), and subsequently being absorbed by the secondary dressing ${ }^{63}$.

\section{WOUND DRESSINGS FOR LOCAL DELIVERY OF GROWTH FACTORS}

\subsection{Wound dressings as GF delivery platform}

Modern wound dressings are traditionally used to protect the wound from contamination, and only take a passive part in the wound healing process. In addition to protecting the wound, these dressings are designed to generate the appropriate environment for healing through control over moisture, drainage of excess fluid or infections. The latest generation of dressings (bioactive dressings) have functions that go beyond being a physical barrier by actively improving the wound healing rate, enhancing the full regeneration of the skin while reducing the formation of resulting scars ${ }^{64}$. Dressings can also be exploited as a platform to deliver active pharmacological agents (medicated dressings) directly to the healing tissue. 
A straightforward strategy to apply GFs relies on preparing more complex tissueengineered constructs to mimic the cell bulk and intricate structures of native tissue. Wound dressings are therefore an ideal delivery platform for GFs, making possible a controlled delivery in the proximity of the wound, avoiding or reducing side effects and exposure of non-target sites. Furthermore, proper engineering of the scaffolds also makes possible a temporal patterning, where the concentration of signaling molecules is maintained within a therapeutic range for periods that depends on the specific timing of repair. The proper delivery of GFs to the wound bed in time and space has recently become a vital issue in wound healing and has led to an explosion of interest in developing biological wound dressings. The control of the local dose and finely tuned spatiotemporal release of GFs, which reproduces their natural physiological presentation to cells, is essential to achieving a successful wound healing outcome ${ }^{65}$. Finally, the integration of GFs into advanced biomaterial-based wound dressings could meet the requirements for achieving successful healing of the injured tissue while protecting the macromolecules from degradation in the harsh wound environment.

In this context, bioactive natural (e.g., sodium alginate, gelatin, hyaluronic acid, collagen, and chitosan) and synthetic [e.g., poly(lactic-co-glycolic acid) (PLGA), polyethylene oxide (PEO), polyvinyl alcohol (PVA), polyurethane] polymers have already been processed using different technologies to obtain advanced wound dressings incorporating a variety of GFs. These biomaterial-based biological delivery systems include, but are not limited to, hydrogels, electrospun nanofibrous scaffolds, injectable gels, and 3Dprinted polymeric scaffolds, which can be used to deliver biological molecules and even cells. Single or multiple GFs can be loaded in these systems using two main strategies: i) prepare the dressing and then load GF(s) or ii) incorporate GF(s) before shaping the dressing. Direct blending into the polymeric matrix (into the whole matrix or preparing a coreshell construct), conjugation through covalent surface chemistry, entrapment of loaded micro/nanoparticles into scaffolds, and combination of these techniques, have been explored for the delivery of therapeutic biological molecules to wounds.

The design and technological development of wound dressings loaded with GFs take advantage of the progress made in biomaterial engineering and continuing advances in understanding the underlying biology of tissue repair and regeneration ${ }^{66}$. The research on this topic can be divided into two main areas: i) the selection of the proper scaffold based on physicochemical properties (e.g., base material, porosity, stiffness, cell recruitment and growth) and ii) the development of procedures to load GFs into a defined matrix (noncovalent integration and covalent immobilization). The conjugation of these strategies can provide a new generation of advanced GF-loaded wound dressings to treat otherwise difficult-to-heal wounds. The strategy of immobilizing GFs in the dressing through covalent bonding will not be covered in this review.

\subsection{Strategies to integrate GFs in wound dressings}

Wounds are dynamic environments, and the proper timing of administration of active compounds is crucial. The control of the time- and space-dependent levels of morphogen 
cues released from a 3D construct is a critical factor in developing tissue-engineering strategies ${ }^{67}$. This concept, together with the constant development of scaffold processing technologies, is the driving force behind the development of advanced systems for wound healing which provides more efficient treatment options for difficult-to-heal wounds compared to traditional dressings.

The incorporation of free GFs in preformed dressings is perhaps the simplest preparation method and has the significant advantage that optimized dressing properties are not substantially affected by the presence of biomolecules (as these are typically loaded in low doses). In these types of systems, desorption is the primary process controlling the delivery rate, although dressing composition and the physico-chemical properties of the GFs are also of utmost importance.

In the case of incorporating GFs before dressing production, it is essential to consider the nature of the material. When dealing with hydrophilic materials, the choice of the crosslinking method is the most important formulation challenge. A crosslinking procedure that does not involve steps potentially detrimental to stability of GFs should be used to prepare hydrogel-based dressings. lonic crosslinking is one of the most popular methods in this sense. It is much more difficult to entrap free GFs into a non-gel-like scaffold of hydrophobic polymers such as biodegradable polyesters, where specific processing methods are used to provide the needed features (e.g., porosity). In most cases, these methods work in the presence of an organic/aqueous solvent interface (e.g., emulsion techniques), elevated temperatures (e.g., polymer melt processing), or high mechanical stress, which are all conditions that are unfavorable for the stability of biological molecules. For this reason, mild fabrication techniques, such as gas-foaming or electrospinning, have been extensively investigated for preparing GF-loaded wound dressing to provide a reservoir of active molecules for controlled local delivery to the wound. A further challenge in producing these dressing is the control of morphology, i.e., generating a proper pore size distribution for exudate management, gas exchange, polymer degradation, and cell recruitment.

Although the dispersion of GFs in a polymeric matrix presents several shortcomings such as low loading efficiency, high burst release, protein aggregation, and denaturation, it has been widely explored in the literature ${ }^{68-74}$. Simple dispersion of GFs does not always offer the necessary control over kinetics and extent of release even when it is possible to modify the release rate from the scaffolds via the interaction between GFs, and specific biopolymers or biomolecules ${ }^{75}$. Though a rapid release from the dressing is advantageous to provide fast therapeutic effect in specific cases, (e.g. antimicrobials) it is necessary to provide finer control over temporal release patterns if the final goal is to act on specific molecular mechanisms chronologically.

Incorporating micro- and nano-sized particles in wound dressings is a powerful means to overcome these shortcomings. These systems promise new wound-healing strategies since they show excellent formulation versatility and the advantage of protecting bioactive cargo and controlling its release rate ${ }^{76}$.

Different polymers can be used to prepare microspheres (MPs) and nanoparticles (NPs) for wound-healing applications ${ }^{77}$. PLGA is a copolymer commonly used to prepare NPs and MPs given the ease of modulating the release rate of the bioactive cargo by varying 
the monomer ratio, the molecular weight of the polymers and the chemistry of the end groups. PLGA is biocompatible and completely biodegradable, and interestingly the lactate released during its degradation has been shown to promote wound healing ${ }^{78,79}$. In the field of wound healing, particular emphasis was given to the use of PLGA NPs and MPs to enhance angiogenesis through sustained VEGF release from biocompatible matrices ${ }^{78,80}$. Chitosan is another polymer frequently used as a base material to prepare NPs and MPs releasing biological macromolecules. In addition to its biocompatibility and biodegradability, the main advantage of chitosan for wound healing lies in its antimicrobial properties due to interaction with the negatively-charged microbial cell membrane, leading to alterations in cell permeability ${ }^{81}$. Many other synthetic copolymers such as poly(lactic acid) (PLA), and poly( $\varepsilon$-caprolactone) $(\mathrm{PCL})$, as well as natural polymers such as gelatin, alginate, and hyaluronic acid, are among the materials that have been investigated to prepare MPs and NPs for wound delivery $77,82,83$. By altering the composition, concentration, molecular weight of the components, or drug loading method, it is possible to release single or multiple GFs in a temporally controlled fashion and adjusting the release kinetics of each entrapped GF. An interesting example of the multiple possibilities offered by micro- and nanotechnologies was reported by Vijayan and co-authors. They prepared a multi-cargo delivery system where two GFs (VEGF and bFGF, both involved in the proliferation of various cell types associated with the healing process) were entrapped inside PLGA NPs by the solvent diffusion method, and an antimicrobial peptide (K4) was conjugated to the NPs by carbodiimide chemistry ${ }^{84}$.

The integration of NPs and advanced dressing in a single composite system offers a further improvement, because it is possible to control the temporal gradients by placing one or more delivery systems in a predetermined position of the dressing to provide preprogrammed signal cues. In this context, cutting-edge dressing preparation technologies have made possible the preparation of a new class of dressings where the creation of welldefined spatiotemporal gradients allows a precise stimulation of physiological repair mechanisms at the molecular level (Fig. 3). 


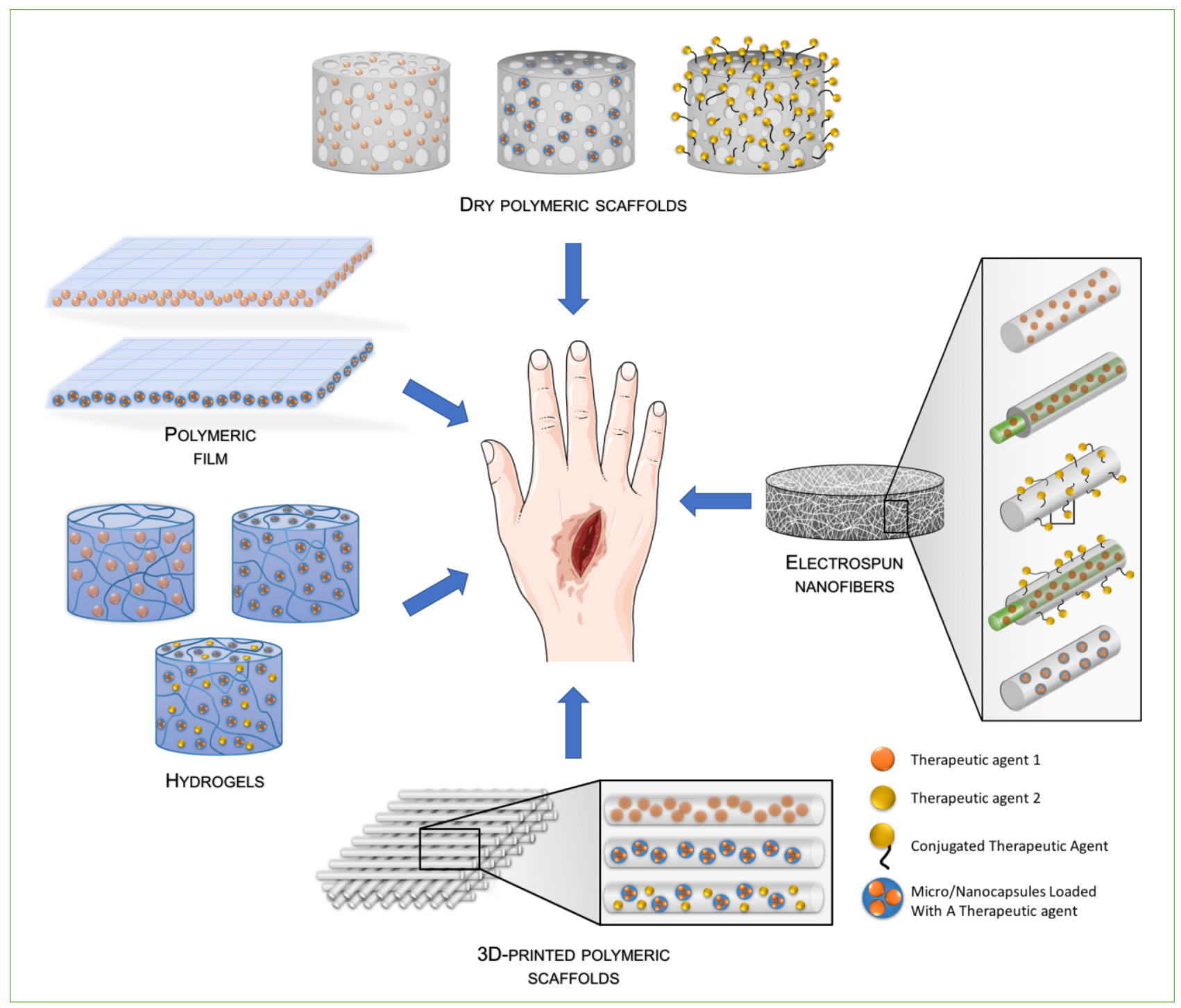

Figure 3. Different technologies recently proposed for the controlled release of GFs from advanced wound dressings. Single or multiple GFs can be loaded in different polymeric matrix structures using appropriate methods. Direct blending into the polymeric matrix (into the whole matrix or preparing a core-shell construct), covalent conjugation on the surface of the scaffold, entrapment of MPs/NPs into scaffolds and the combination of these techniques have been explored for the delivery of biological molecules to wounds. The final goal is to replicate the crucial ideal wound microenvironment required for proper tissue regeneration through the correct spatiotemporal release of bioactive molecules.

\subsection{Wound dressings loaded with GFs}

Advances in development of biomaterials have enabled significant progress in biology and medicine, leading scientists and clinicians to rethink many of the clinical strategies previously used ${ }^{66}$. Wound dressings are a clear example of how a medical device traditionally considered only for wound protection can be engineered to exert a wound healing enhancement action. Modern dressings are designed to protect the wound and generate the appropriate environment for healing through control over moisture, drainage of excess fluid or infections. They are also promising platforms for drug delivery to the wound, especially in the case of chronic wound management, where prolonged exposure to the 
bioactive molecules is necessary, and the healing occurs typically over long periods. Hydrated wound dressings (hydrogels) and dry wound dressing (sponges, foams, films, and scaffolds), on the other hand, provide superior exudate management and prolonged residence at the wound site ${ }^{63,64}$. These two characteristics alone already improve the management of chronic wounds, but the further possibility of loading these dressings with bioactive molecules, makes them suitable for use as in situ delivery platforms. However, it is essential to carefully select the loading strategies as they have a significant impact on the spatial and temporal release kinetics of these molecules and their stability. Table 2 shows a summary of GF-loaded dressings and corresponding strategies for GF encapsulation. 
Table 2. Summary of GF-loaded wound dressings and method of GF loading

\begin{tabular}{|c|c|c|c|c|c|c|}
\hline Type of dressing & $\begin{array}{l}\text { Growth } \\
\text { factor }\end{array}$ & $\begin{array}{l}\text { Drug loading } \\
\text { method }^{\mathrm{a}}\end{array}$ & In vitro model & In vivo model & Main findings & Ref. \\
\hline $\begin{array}{l}\text { Hyaluronate/ } \\
\text { collagen lyophilized } \\
\text { matrix }\end{array}$ & $\begin{array}{l}\text { Structurally } \\
\text { stabilized EGF } \\
\text { and bFGF }\end{array}$ & Mixing & $\begin{array}{l}\text { Cell proliferation assay } \\
\text { using Balb/3T3 and } \\
\text { NIH/3T3 fibroblasts }\end{array}$ & $\begin{array}{l}\text { Full-thickness wound ( } 10 \mathrm{~mm} \\
\text { diameter) in type I and type II } \\
\text { diabetic mice }\end{array}$ & $\begin{array}{l}\text { The structurally stabilized GFs have a higher purity } \\
\text { and stability for long periods at room temperature } \\
\text { compared to the normal GFs. When loaded onto a } \\
\text { hyaluronate-collagen matrix they were able to } \\
\text { promote wound healing in a diabetic ulcer model }\end{array}$ & 68 \\
\hline $\begin{array}{l}\text { Crosslinked } \\
\text { PVA/alginate } \\
\text { hydrogel }\end{array}$ & EGF & Mixing & $\begin{array}{l}\text { Cell proliferation assay } \\
\text { using Balb/3T3 fibroblast }\end{array}$ & $\begin{array}{l}\text { Excisional wound }(1.3 \times 1.3 \mathrm{~cm}) \\
\text { on the back of diabetic rats }\end{array}$ & $\begin{array}{l}\text { The EGF-containing hydrogel had a prolonged and } \\
\text { sustained release of bioactive EGF enhancing the } \\
\text { therapeutic potential }\end{array}$ & 69 \\
\hline $\begin{array}{l}\text { Polyurethane } \\
\text { hydrogel }\end{array}$ & FGF-2 & Mixing & $\begin{array}{l}\text { Antimicrobial efficacy tested } \\
\text { on } P \text {. aeruginosa and } S \text {. } \\
\text { aureus }\end{array}$ & $\begin{array}{l}\text { Full-thickness wound }\left(0.785 \mathrm{~cm}^{2}\right. \\
\text { circular area) on the back of rats }\end{array}$ & $\begin{array}{l}\text { The polyurethane hydrogel incorporating FGF-2 } \\
\text { accelerates wound healing and reduced scar } \\
\text { formation. The polyurethane hydrogel was easier to } \\
\text { strip off than commercial wound dressing, which } \\
\text { prevents additional injury to the wound during } \\
\text { dressing change }\end{array}$ & 70 \\
\hline $\begin{array}{c}\text { Hyaluronic } \\
\text { acid/collagen sponge }\end{array}$ & $\begin{array}{l}\text { EGF (in } \\
\text { association with } \\
\text { a vitamin C } \\
\text { derivative) }\end{array}$ & Mixing & $\begin{array}{l}\text { Cytokine production by } \\
\text { fibroblasts was assessed in } \\
\text { a wound surface model } \\
\text { using a fibroblast- } \\
\text { incorporating collagen gel } \\
\text { sheet }\end{array}$ & $\begin{array}{l}\text { Excisional wound }(1.5 \mathrm{~cm} \times 2.0 \\
\mathrm{cm}) \text { on the dorsal region of } \\
\text { genetically modified type II } \\
\text { diabetic mice }\end{array}$ & $\begin{array}{l}\text { The EGF/vitamin C-wound dressing had a strong } \\
\text { potential to enhance the in vitro production of both } \\
\text { VEGF and HGF. In the diabetic model, the EGF/VC- } \\
\text { wound dressing effectively promoted granulation } \\
\text { tissue formation associated with angiogenesis }\end{array}$ & 71 \\
\hline Gelatin Film & EGF & Mixing & $\begin{array}{l}\text { Cell proliferation assay on } \\
\text { NIH3T3 fibroblasts and } \\
\text { PAM212 keratinocytes }\end{array}$ & $\begin{array}{l}\text { Partial-thickness skin wounds } \\
\text { made on dorsa of hairless dogs }\end{array}$ & $\begin{array}{l}\text { Wound closure in wounds treated with EGF- } \\
\text { containing gelatin sheets was accelerated when } \\
\text { compared to the wounds treated with control } \\
\text { dressings. Earlier re-epithelialization of the epidermis } \\
\text { and highly regulated repair of ECM in the dermis } \\
\text { were also found }\end{array}$ & 85 \\
\hline $\begin{array}{l}\text { Light-cured glycol } \\
\text { chitosan hydrogel }\end{array}$ & $\begin{array}{l}\text { PDGF-BB and } \\
\text { VEGF }\end{array}$ & Mixing & $\begin{array}{l}\text { Cell proliferation assay } \\
\text { using L929 murine } \\
\text { fibroblasts }\end{array}$ & $\begin{array}{l}\text { Full-thickness skin wound }(5 \mathrm{~cm} \\
\text { diameter) in Balb/C mice }\end{array}$ & $\begin{array}{l}\text { The crosslinking by visible light irradiation of modified } \\
\text { glycol chitosan improved the physical property of } \\
\text { hydrogels and showed a combined sustained release } \\
\text { of PDGF-BB and VEGF, significantly accelerated the } \\
\text { wound healing process facilitating the angiogenesis }\end{array}$ & 86 \\
\hline $\begin{array}{l}\text { Hyaluronic acid } \\
\text { sponge }\end{array}$ & EGF & Mixing & - & $\begin{array}{l}\text { Excisional wound }(30-\mathrm{mm} \\
\text { diameter) on the abdomen of rats. } \\
\text { Excisional wound }(1.5 \mathrm{~cm} \times 2.0 \\
\mathrm{cm} \text { ) on the dorsal region of } \\
\text { genetically type II diabetic mice }\end{array}$ & $\begin{array}{l}\text { EGF-free-dressing and EGF-dressing decreased } \\
\text { wound size and promoted granulation tissue } \\
\text { formation associated with angiogenes more } \\
\text { effectively than a commercially available alginate } \\
\text { dressing }\end{array}$ & 87 \\
\hline
\end{tabular}


Layer-by-layer

chitosan/alginate

films

Chitosan-silver hydrogels

Chitosan film

\section{Chitosan/alginate}

hydrogels

Polyurethane foam

EGF

Mixing

Chitosan-crosslinked collagen sponge

bFGF (in

Silver ions)

Mixing

Mixing

Mixing
Human primary

keratinocytes were used to

measure the effects of

released rhEGF on in vitro differentiation

Cell proliferation assay using L-929 mouse fibroblasts

Cytotoxicity on L929 murine fibroblasts using the agar overlay assay

E. coli and S. aureus to evaluate the antibacterial property

In vitro cytotoxicity and cell migration assay in $\mathrm{HaCaT}$ keratinocytes and CCD986skin fibroblasts

Cell proliferation assay Skin trauma model $(1.8 \mathrm{~cm})$ using 3T3 cells or NRK52E produced through deep II scald cells

Cell proliferation assay Subcutaneous implantation in using Balb/3T3 fibroblast on the back of type 1 diabetic rat

Dorsal burn wound (8-mm diameter) on C57BL/6 female

Excisional steroid-suppressed wound healing model in rat

\section{Full thickness wounds in white} pigs

In vivo wound closure assay using a rat's tail vein bleeding model and an in vivo deep second-degree scald wound rat model

Full-thickness excisional wound $2 \times 2 \mathrm{~cm})$ on the back of male diabetic rats healthy Sprague Dawley male rats
The application of pluronic/chitosan hydroge containing EGF significantly enhanced the keratinocyte proliferation of epidermal cells, increasing the wound healing rates

In steroid-treated rats, IGF-I loaded dressing enhanced excisional healing, stimulating SMA- as well as PCNA-expression and increased the formation of granulation tissue

The smart nanopolymeric membranes were capable of a burst release of EGF in the presence of lysozyme

The immobilization of silver in the hydrogel not only reduced the side effects of silver on the bioactivity of bFGF, but also allowed elution of bFGF in a controlled release manner

Although continuous release of EGF in chitosan film accelerates epithelialization, the benefit of the combination of EGF in chitosan over the use of chitosan alone could not be determined

The porous 3D architecture of the chitosan/alginate hydrogels enabled sufficient loading and release of EGF, improved cell proliferation, and efficient in vivo incised wound closure and scald wound healing.

The polyurethane foam could release EGF in a sustained manner increasing the cell proliferation rate in vitro. These dressings were found to be effective in enhancing the regenerative process following skin injury in a diabetic rat model by stimulating skin regeneration

The dressing containing FGF had the shortest healing time, the quickest tissue collagen generation, the earliest and highest TGF- $\beta 1$ expression and dermal cell proliferation (PCNA expression), compared to the control treatment

The modified bFGF could be localized longer at the surface of chitin films compared to bFGF, and retained the FGF biological activity in inducing fibroblast proliferation, inducing cellularization and vascularization 
Poly(ether)urethanepolydimethylsiloxane /fibrin-based scaffold

Mixing

$$
\text { (PLGA) }
$$

\section{Mixing}

Gelatin sponges

EGF microencapsulation (gelatin)

Dextran hydrogel

Chitosan-hyaluronic acid composite sponge

\section{PLA-10R5-PLA} hydrogel

Alginate/poly $(\mathrm{N}$ isopropylacrylamide) composite hydrogel

Chitosan/PVP

physical hydrogel

Polycaprolactone electrospun fibers

\section{EGF and VEGF Microencapsulation (chitosan)}

\section{VEGF}

EGF (in association with curcumin)

bFGF (in association with diclofenac $\mathrm{Na}$ )

(PLA-10R5-PLA block copolymers)

Nanoencapsulation (poly $(\mathrm{N}$ -

isopropylacrylamide)

\section{Nanoencapsulation} (Na carboxymethy

chitosan), conjugation

Nanoencapsulation (chitosan),
Full-thickness wound $(8 \mathrm{~mm}$ diameter) on the back of male diabetic mice

Circular full thickness wounds diameter $0.8 \mathrm{~cm}$, area $0.50 \mathrm{~cm}$ ) on the back of 3-month-old male rabbits

Dorsal burn wound $(2 \mathrm{~cm}$

cytotoxicity assay using human fibroblast

Cell viability, attachment and proliferation studies on human umbilical vein endothelial cells (HUVECs) and human dermal fibroblast (HDF)

\section{In vitro cytotoxicity assay} using HEK293 and 3T3 cells

In vitro cytotoxicity assay using human skin fibroblast (HSF) electrospinning

Cell proliferation assay $3.14 \mathrm{~cm}^{2}$ circular area) on the back of male diabetic rats

Cell proliferation and migration assay using fibroblasts diameter) on rats

The application of scaffolds containing VEGF and bFGF in free form or loaded into NPs induced significant granulation tissue formation, collagen deposition and re-epithelialization, and accelerated wound closure compared to control scaffolds and scaffold/unloaded NPs

The dressings were biocompatible and did not cause any mononuclear cell infiltration or foreign body reaction. Minimum differences in activity between free EGF and EGF-loaded microspheres at low doses. With increasing dose, the controlled release of EGF from microspheres provided a higher degree of reduction in the wound areas

The dextran hydrogel loaded with chitosan microparticles containing the two GFs promoted a faster wound healing with no signs of a local or systemic inflammatory response

HUVECs seeded on VEGF loaded sponges showed capillary like tube formation which was absent in control sponges

Excellent wound healing activity in vivo through increasing granulation tissue formation, collagen deposition, and angiogenesis

The drug-loaded composite hydrogels had good physicochemical properties, no cytotoxicity, the ability to control the release rate of diclofenac $\mathrm{Na}$ and bFGF, and an overall better in vivo healing effect compared to the controls

The polymer-conjugated EGF was more stable against proteases and showed improved fibroblast

Excisional wound $(2 \mathrm{~cm}$ diameter, cell proliferation in vitro. After 15 days in vivo, the wound area was significantly smaller than the contro group and showed histological parameters equal to positive wound control group
The controlled release of PDGF-BB increased fibroblast migration and proliferation 
PCL, chitosan, and collagen three-

Commercial

polyurethane film

dressing

(Tegaderm ${ }^{\mathrm{TM}}$ )

Poly(ethylene

argininylaspartate

digylceride) matrix

Silk fibroin hydrogel

FGF1

PEG cross-linked

cotton-like chitosan scaffold

Gelatin gel sheet

Crosslinked fish gelatin

EGF

Absorption

Chitosan-silica

hybrid membrane dressing

Lysozyme microbubbles (LYMBs)

Heparin immobilization

immobilization

Absorption preformed preformed membrane
Antimicrobial efficacy tested on $P$. aeruginosa and $S$.

Full-thickness wound $\left(400 \mathrm{~mm}^{2}\right)$ aureus. HDFs to test the in in rats vitro bioactivity

Antimicrobial efficacy tested on $S$. aureus

Full-thickness skin wound model ( $8 \mathrm{~mm}$ diameter) in a mouse model

Full-thickness wound $(6 \mathrm{~mm}$ diameter) in C57BL/6 mice A silicone ring was used to reduce skin contraction upon wounding

In vitro scratch assay using fibroblast L929 cells

Full-thickness wound $(15 \mathrm{~mm}$ diameter) in the rat

In vitro proliferation studies of HaCaT cells

Excisional wound $(1 \times 1 \mathrm{~cm})$ on the back of adult male rats

Cell cytotoxicity,

proliferation, infiltration and

adhesion studies using

L929 murine fibroblasts

Full-thickness wound $(8 \mathrm{~mm}$ diameter) on the back of mice

Full-thickness wound on male HR-1 albino hairless mice with

Cell proliferation assay using keratinocyte $\mathrm{mm}$ ) on the back
The treated group showed faster epithelialization and angiogenesis

Significant reduction of the duration of wound

two symmetrical circle defects (12 proliferation. This resulted in an improved wound healing, promotion of neovascularization and wound healing, and improvement of the wound prognosis

The controlled release of FGF-2 significantly accelerated wound healing by promoting cell proliferation, stimulating the secretion of VEGF for re-epithelization, collagen deposition, and granulation tissue formation.

Overall improvement of wound healing and decreased the time required to achieve total closure, compared to a commercially available chitosan dressing

The scaffolds could deliver two GFs in a continuous manner and attained stability after 7 days. The GFincorporated crosslinked scaffolds had better healing capacity compared to the control dressing

The proposed dressing could sustain the release of bFGF and conformed to the shape of the wound. Accelerated epithelialization, granulation tissue formation and angiogenesis were observed in vivo

The proposed films prepared with a simple and costeffective process allowed a controlled delivery of EGF for $24 \mathrm{~h}$. Spreading, adhesion and proliferation assays confirmed the excellent adaptability of the cells onto the hydro-film surface without invading the dressing

The hybrid membranes loaded with KGF improved keratinocyte activities such as attachment and

healing process in vivo, compared to the dressing without KGF 


\subsubsection{Wound dressings loaded with free GFs}

As already discussed, free GFs can be directly incorporated within the dressings during the fabrication process, generally mixing the GFs with the polymer(s) before formulating the dressing. The main challenge of this approach is to ensure that the processing conditions do not significantly affect the stability of GFs while still ensuring their sustained release ${ }^{113}$. GF-loaded wound healing scaffolds were prepared by mixing free GFs with different biocompatible materials, such as gelatin ${ }^{85,98,110}$, alginate ${ }^{93,114}$, dextran ${ }^{99}$, polyurethane ${ }^{70,94}$, hyaluronic acid ${ }^{71}, 100,115$, and chitosan ${ }^{95,} 96$ (Table 2). Their hydrophilic nature makes a homogeneous dispersion of GFs simple to obtain, whereas the crosslinked network makes the scaffolds handy and easy to apply on wounds, even in the presence of exudate. The local concentration and the spatiotemporal gradients of a molecule depend upon a delicate balance between the transport properties of the scaffold, the binding and degradation rate of the molecule and its release rate ${ }^{65}$. The design of wound dressings loaded with free GFs must consider that the release profiles are mainly related to the morphological properties of the dressing. The typical release profiles of a GF incorporated into hydrogels without any further modification show a rapid burst release during the initial swelling phase, eventually followed by the extended release of the GF due to viscous resistance of the resulting gel network ${ }^{116}$. Due to the relatively small size of the GFs compared with the pore of the polymeric network, the simple dispersion in a hydrogel-like scaffold does not always offer the necessary control over release kinetics and extent of release. Alternatively, an extended release can be achieved with the immobilization of the GFs within the biodegradable hydrogel, making the release of the immobilized factor controlled by the degradation rate of the hydrogel $108,109,111,112,115$. The fabrication of more tunable polymeric scaffolds using hydrophobic polymers such as biodegradable polyesters can provide the drug release flexibility needed in wound healing. However, these materials often involve the use of organic solvents, high electric voltage, or high mechanical stress for their processing, which may inactivate GFs.

\subsubsection{Wound dressings loaded with encapsulated GFS}

Micro and nanoencapsulation can be a valid option to protect GFs during dressing formulation and to achieve the long-term exposure required for the delivery of GFs to chronic wounds ${ }^{76,117}$. The incorporation of GFs into micro- and nano-sized particles offers excellent versatility in their application, boosting the development of innovative wound-healing dressings. For example, the delivery of GFs can be finely regulated by using GFs loaded in microencapsulated systems ${ }^{98}$, or by a combination of encapsulated and free GFs ${ }^{118}$ to implement temporal and spatial control of the actions of these biomolecules, mimicking the physiological action sequence and providing the most effective outcome. Using these approaches, various innovative polymeric wound dressings capable of controlled release of GFs have been developed and tested using in vivo and in vitro models (Table 2).

A delivery system based on a heparin-based coacervate loaded with FGF-2 was developed by Wu et al. ${ }^{107}$. The FGF2 coacervate was successively loaded into a poly(ethylene argininylaspartate digylceride) matrix and showed prolonged release, with 
only $60 \%$ of the GF being released in 17 days, which can support long-term delivery of the GF to the wound environment. Recently, a new integrated wound healing platform integrating EGF-coated lysozyme microbubble was developed ${ }^{106}$. GFs can also be coencapsulated with another active component (e.g., the antioxidant curcumin, as described by Li et al. ${ }^{101}$ or the anti-inflammatory diclofenac sodium as described by Lin et al. ${ }^{102}$ ) to achieve a dual-release drug delivery system which can improve wound healing by acting through different mechanisms. Despite the promising studies in vitro and in vivo, large clinical trials involving the wound delivery of GFs from these integrated platforms have often failed to demonstrate results of clinical significance.

The application of GFs in wound healing has mostly focused on delivering a single dose, although the combined action of different GFs improved the healing process in the wounded skin of diabetic mice better than single-agent treatment ${ }^{119}$. A representative example of how the temporal aspects of GF release, is the key role exerted by VEGF and PDGF, respectively, in the earlier and later stages of angiogenesis ${ }^{120}$. In this case, careful manipulation of the physical and chemical properties of the core-shell microcapsules entrapping the GFs, modified their release to closely mimic the wound physiological scenario and improve angiogenesis, compared with the traditional bolus administration ${ }^{121}$. Based on the same concept, Losi et al. developed a poly(ether)urethane-polydimethylsiloxane/fibrinbased scaffold containing PLGA NPs loaded with VEGF and bFGF97. The scaffold application on full-thickness dorsal skin wounds significantly accelerated wound closure on day 15 compared to scaffolds without GFs or containing unloaded PLGA NPs. However, the closure rate was similar to that observed in mice treated with scaffolds containing free VEGF and bFGF. A similar combination of VEGF and bFGF was used by Vijayan and co-workers to obtain a PEG cross-linked cotton-like chitosan scaffold able to constantly deliver both GFs and attain stability after 7 days ${ }^{109}$. The application of a dextran hydrogel loaded with a combination of EGF and VEGF encapsulated in electrosprayed chitosan microparticles was shown to promote faster wound healing with no signs of local or systemic inflammatory response ${ }^{99}$. Interestingly, a single application per week of the hydrogel loaded with GFs reduced the wound area faster than the application of free EGF and VEGF every two days.

\subsubsection{Nanofibrous structures as wound dressings}

A very popular approach to develop novel multifunctional platforms for the local delivery of GFs to the wound is the production of nanofibers by electrospinning ${ }^{122-125}$. These nanofibers can control and guide the wound healing process by integrating controlled release strategies within scaffold materials and can be very useful for the development of innovative wound dressings. By adjusting the fiber diameter, drug-to-polymer ratio, and/or porosity or selecting the most appropriate polymers for the production of these scaffolds, it is possible to finely tune the release rate to meet specific clinical applications ${ }^{126}$. As a result, electrospinning is now recognized as a straightforward, facile, and versatile method to prepare nanostructured drug delivery systems ${ }^{123}$. Various electrospinning techniques, such as blending, specific or nonspecific surface modifications, coaxial electrospinning, emulsion electrospinning, and combination of electrospinning with other conventional techniques, 
have been applied for the development of GF-loaded wound dressing yielding various levels of success ${ }^{127,128}$.

The incorporation of GFs in the polymeric solution before the electrospinning process is the simplest way to produce drug-loaded nanofibers. Blend electrospinning was successfully used to prepare several electrospun membranes functionalized with GFs for use as wound dressings ${ }^{124}$. These membranes have a drug release profile dependent on the diffusion coefficient of the single molecule, often resulting in a significant burst release with consequent reduction of effective treatment time ${ }^{72}$. However, to extend the drug release period, it is possible to prepare multilayer structures consisting of multiple drug-loaded layers, rate-controlling barrier layers, and cover layers that can be assembled to prepare complex delivery systems where the drug release rate from the dressing can be easily tailored by tuning the properties of the layers containing the drugs and the barrier layers ${ }^{129}$.

Using a combination of encapsulated and free GFs, it is possible to implement temporal and spatial control of drug release as reported by Xie et al. They conceived a biomimetic nano-fibrous scaffold with the fast release of VEGF-loaded PLGA NPs followed by a later release of a beta PDGF dimer (PDGF-BB) dispersed into the polymeric matrix, achieving an accelerated wound healing of a full-thickness rat skin wound model ${ }^{118}$. Antimicrobial agents such as silver sulfadiazine (SSD) can also be loaded into one of the nanofibrous mat layers and released together with GFs to obtain a multilayer wound dressing with multiple effects in chronic wounds ${ }^{105}$. Surface immobilization through covalent bonds with polymeric chains is another way to control GF release ${ }^{130}$. These modified and functionalized nanofibers have a slow and prolonged release, thus overcoming the problems of initial burst release, preserving functionality of the GFs and enhancing wound healing. Moreover, surface immobilization can be used to prepare a dual release system as in the nanofibrous scaffold prepared by Dwivedi and co-authors, with the antibacterial gentamicin sulphate loaded into the electrospun fibers and rhEGF covalently immobilized on the scaffold surface ${ }^{131}$.

Coaxial electrospinning can be considered an evolution of electrospinning, which uses two concentrically aligned capillaries which allows the formation of fibers with a coreshell structure ${ }^{132}$. The coaxial electrospinning process allows a one-step encapsulation of fragile, water-soluble bioactive agents, including GFs, DNA, and even living organisms, into core-shell nanofibers, eliminating the damaging effects due to direct contact of the agents with organic solvents or harsh conditions during emulsification. Compared to blend electrospun fibers, coaxial electrospun fibers have a more uniform structure, homogenous protein distribution in the core of the fibers, and they better preserve the protein activity, resulting in a longer sustained release ${ }^{129}$, 133. Furthermore, coaxially electrospun nanofibrous scaffolds easily allow the integration of multiple GFs. For example, coaxial electrospun fibers were used for the dual release of EGF and bFGF, with bFGF loaded into the core of the core-shell fibers, while EGF was chemically immobilized on the shell surface $^{134}$. The different release rates (fast release in the first 12 hours for bFGF, and a sustained release up to 7 days for EGF) caused a temporal distribution of the GFs, allowing bFGF to act in the initial stages of healing, promoting cell migration and proliferation, whereas the EGF effect was more sustained over the healing process. The in vivo studies undertaken on burns created on diabetic C57BL/6 female mice clearly showed that the 
controlled release of EGF and bFGF from nanofibers further accelerated the proliferation of epidermal cells and wound closure than controls, EGF-loaded nanofibers, and bFGF-loaded nanofibers. Animals treated with EGF/bFGF nanofibers improved collagen and keratin accumulation better than the controls ${ }^{134}$.

Electrospun composite nanofibers can also be designed with a staged release of more than two GFs for sequential release at the wound site. According to Lai and coauthors ${ }^{135}$, multiple GFs, including bFGF, EGF, VEGF, and PDGF, can be encapsulated either in nanofibers or in NPs and released over 1 month via gradual degradation of nanofibers/nanoparticles simulating the temporal release of regulatory factors in the normal wound healing process ${ }^{135}$. The initial delivery of bFGF and EGF bio-mimics the early stage of the wound healing process, whereas slow controlled release of VEGF and PDGF-BB imitates the late stage of skin reconstruction promoting re-epithelialization, dermal reconstruction and formation of mature vasculature as confirmed by in vivo studies on streptozotocin-(STZ)-induced diabetic rats.

Emulsion electrospinning is a relatively simple technique to fabricate nanofibers that allow a more controlled release of GFs from a nanofibrous mat. Bioactive compounds can be well incorporated in either water-in-oil (W/O) or oil-in-water $(\mathrm{O} / \mathrm{W})$ emulsions and electrospun to directly encapsulate hydrophilic or hydrophobic compounds into core-shell fibers, respectively. By dissolving the GFs in the water phase of the W/O emulsion, it is possible to protect them from the harsh solvent required to dissolve the polymer. However, when compared with coaxial electrospinning, this method lacks well-defined control over the location of the therapeutic agent within either the core or shell of the structure ${ }^{136}$. Several studies have proven that emulsion-based electrospun nanofibers can enhance the encapsulation efficiency, stability, and bioavailability of bioactive compounds and achieve targeted delivery and controlled release ${ }^{137}$. Emulsion electrospinning has proven successful in preparing novel nanofibrous dressings for wound healing applications, and with this technique, core-sheath nanofiber dressings loaded with $b F G F^{138}$, EGF ${ }^{139-141}$ and VEGF ${ }^{142}$ were developed.

After years of research on this topic, there is no doubt that electrospun nanomaterials can play an important role in biomedical applications. The flexibility and versatility of the electrospinning process make this technology very useful in wound dressing application, however, unfortunately, it has certain limitations in clinical practice. Due to its conventional setup which is usually quite bulky and requires high-voltage supply, special laboratories are needed to prepare the dressings, which will then be applied to the patients. To overcome these limitations, a battery-operated portable handheld electrospinning apparatus (BOEA) was recently developed, replacing the typical high-voltage generator with a high-voltage converter making the apparatus no longer dependent on the electrical supply (Fig. 4A). This small and lightweight (about $120 \mathrm{~g}$ ) apparatus can work with two AAA batteries and has the ability to electrospin different polymers, such as PCL, PLA, polyvinylpyrrolidone (PVP), polystyrene, and polyvinylidene fluoride (PVDF), into fibers. The development of this kind of portable battery-operated handheld apparatus could lead to consideration of electrospinning for practical day-to-day applications such as personal healthcare devices, especially in biomedical fields such as skin damage, wound healing and rapid hemostasis ${ }^{143-145}$.

Melt electrospinning writing (melt electrospinning combined with moving collectors) 
is another relatively new processing technology for producing fibrous materials from polymer melts, and it can be considered as a type of 3D printing technology (Fig. 4B) ${ }^{146,147}$. With this technology, it is possible to fabricate complex 3D structures with up to millimeter thickness based on the accurate deposition of small fibers upon each other, leading to flexible constructs that enable even relatively rigid polymers to be fabricated as soft, compliant structures. Moreover, the process avoids the use of toxic solvents with obvious advantages. Finally, by combining 3D printing and electrospinning, it was possible to prepare hybrid hierarchical scaffolds consisting of alternating layers of 3D-structured/microsized polymer strands and nanofiber webs, which improved the final biological properties of the scaffolds ${ }^{148}$. According to the authors, such scaffolds would avoid the shortcomings of conventional 3D dispensed structures with electrospun fiber webs, such as pore size being too large relative to the seeded cells, unfavorable conditions for initial cell attachment, and low mechanical properties to support a 3D structure.
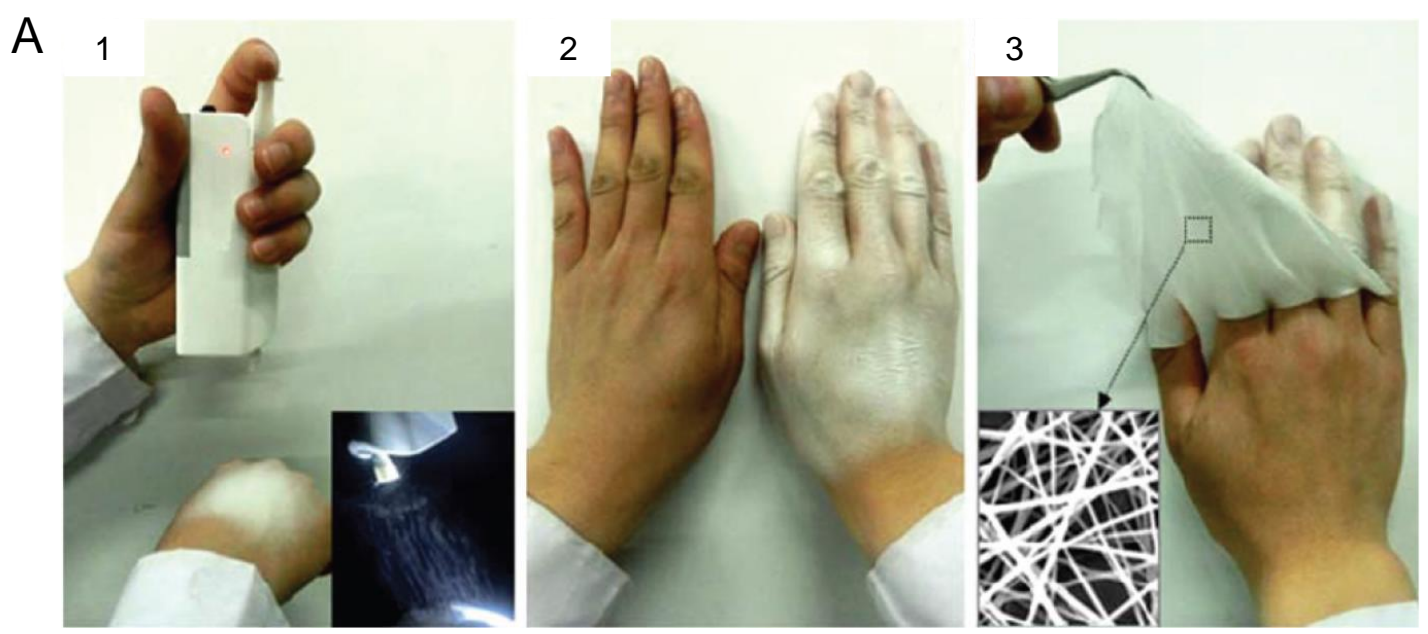

B

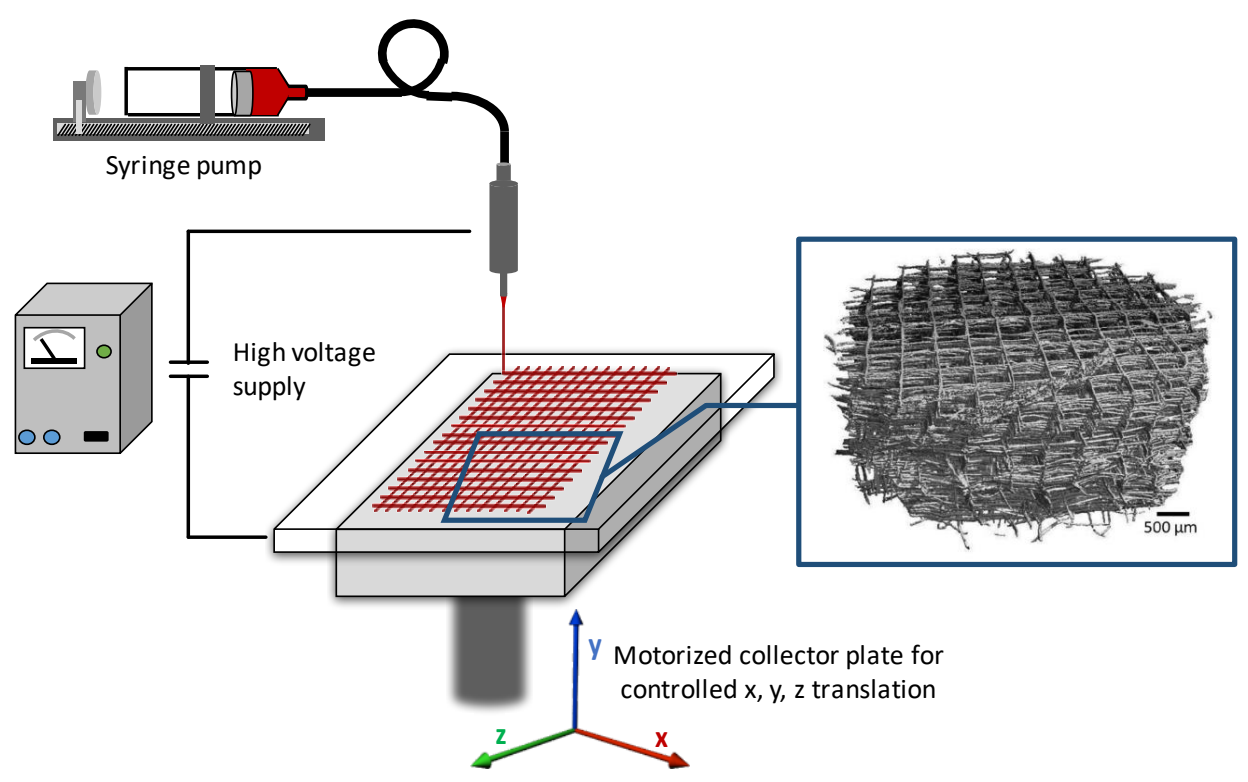

Figure 4. A) The process of deposition of PLA fibers directly onto the skin using the battery-operated electrospinning apparatus (BOEA). (1) BOEA was operated by one hand and the inset shows the spinning process of the BOEA in a dark environment. (2) A PLA fibrous membrane was fabricated on another hand within two minutes. (3) The electrospun fibrous membrane has good flexibility and compactness. The inset is 
the SEM image of the electrospun fibers. Reproduced from Xu et al. ${ }^{144}$ with permission from The Royal Society of Chemistry; B) Novel direct writing melt electrospinning platform with dual voltage power supplies for improved fiber deposition control. The negative power supply attached to a moving collector plate is the defining difference in this system compared to traditional systems. An X-ray microtomography $(\mu \mathrm{CT})$ of a scaffold obtained by melt electrospinning with an $x-y$ fiber spacing of $500 \mu \mathrm{m}$ is reported in the inset as an example (reproduced from Ristovski et al. ${ }^{147}$ with permission from American Vacuum Society).

\subsection{Blood derived products as GF reservoir for wound dressings}

\subsubsection{Platelet-rich plasma (PRP) and platelet-rich fibrin (PRF)}

Blood derived products have demonstrated the capacity to enhance healing and stimulate the regeneration of different tissues. In 1979, Ross et al. ${ }^{149}$ were the first to describe the use of platelets as a reservoir of GFs, and since then topical treatments with platelet derivatives have been increasingly described as having the capability to accelerate wound healing and to aid in tissue repair ${ }^{150,151}$. Upon degranulation, platelets release a pool GFs and proteins involved in tissue regeneration such as PDGF, PDEGF, EGF, VEGF, FGF, TGF- $\beta$, IGF, IL-8, TNF- $\alpha$. For this reason, platelets can be considered as a potential source of multiple GFs, and PRP and PRF have been proposed in the clinical management of wounds. PRP is an autologous preparation that concentrates platelets in a small volume of plasma through centrifugation ${ }^{152,}{ }^{153}$, while PRF is a fibrin clot rich in platelets obtained without addition of thrombin. The main advantage of therapy with PRP and PRF gels is the ability to release multiple GFs in their biologically determined ratios, in a similar way to the natural wound healing process via degranulation of $\alpha$-granules ${ }^{154,155}$. For each treatment, autologous PRP or PRF gels must be prepared right before the application using laboratory procedures, causing potential intra-batch differences with variable therapeutic effects after application. However, the use of standardized commercial kits for the autologous PRP or PRF gel preparation, such as the AutoloGel ${ }^{\mathrm{TM}}$ System (Cytomedix, Inc., Rockville, MD, USA), greatly reduces these intra-batch differences, and they are currently indicated for use in DFUs ${ }^{154,156}$. PRP and PRF provide a sustained release of high concentrations of platelet GFs, reducing the early inactivation and degradation of GFs by the numerous hydrolytic enzymes at the wound site, and therefore enhancing healing and vascularization ${ }^{157}$. Although they have demonstrated interesting wound healing activities ${ }^{158-160}$, their efficacy critically depends on how they are made available to the injured tissue.

PRP therapy is considered an advantageous and cost-effective treatment for DFUs even when compared with treatment using advanced wound dressings ${ }^{161,162}$, and acts as a tissue sealant and sustained delivery system for GFs. However, when applied in vivo, the efficacy of the PRP therapy is very limited for a variety of reasons including, but not limited to, preparation methods, donor heterogeneity, and rapid clearance from the site of interest ${ }^{153}, 163,164$. Moreover, its low mechanical strength and fast degradation rate limit its applications in tissue regeneration, especially in large and deep wounds ${ }^{165}$.

Sustained release of PRP using hydrogels has been demonstrated to be a highly potent and effective modality to deliver GFs directly to the wound site. Qiu and co-workers successfully prepared an injectable thermosensitive in situ forming hydrogel of poly(D,Llactide)-poly(ethylene glycol)-poly(D,L-lactide) (PLEL), in which PRP was homogeneously incorporated. When used to treat full-thickness skin defects in rodents, the platform showed 
a significantly higher ability to raise the number of newly formed and mature blood vessels than the control, PLEL and PRP groups. Furthermore, the PRP/PLEL-treated group displayed faster wound closure, better re-epithelialization and collagen formation ${ }^{166}$. In the design of biologically active dressings, the combination of PRP with materials and techniques with well-known effects on wound healing can also offer a further advantage, as demonstrated for chitosan films ${ }^{167}$, collagen/PCL biocomposites ${ }^{168}$, electrospun meshes ${ }^{169}$ or acellular dermal matrix ${ }^{170}$. PRP was also engineered to prepare a hydrogel glue through the addition of photo-responsive hyaluronic acid which generates aldehyde groups upon light irradiation and subsequently reacts with amino groups of autologous PRP171. This hydrogel glue could be conveniently and rapidly prepared in situ, forming a robust cytocompatible hydrogel scaffold with strong tissue adhesive ability, an associated control over GFs release and better therapeutic efficacy when compared with thrombin activated PRP gel in hyaline cartilage regeneration. A gelatin dressing impregnated with PRP releasate (the active soluble part was isolated following platelet activation of PRP) has also been proposed as a sustained release system for the delivery of GFs to wound sites ${ }^{172}$. The use of PRP releasate allows easy control over the concentration of GFs and, at the same time, provides a controlled release to the wound, resulting in a reduction of the wounded area after 21 days compared with the PRP alone.

PRF is a fibrin clot rich in platelets with no thrombin, prepared from centrifuged blood without biochemical blood handling, which belongs to the second-generation of platelet concentrates. The progressive or relatively slow polymerization occurring during centrifugation (as opposed to the rapid polymerization caused by the high thrombin levels needed to prepare PRP) increases the incorporation of the circulating cytokines in the fibrin meshes of the PRF. Furthermore, the autologous GFs are released from PRF in a controllable, relatively slower fashion, and therefore has a more robust and durable effect on cell proliferation and differentiation ${ }^{173}$. Similar to PRP, PRF can also be used as a source of GFs to be included in a wound dressing, and once embedded in a gelatin gel, it can promote angiogenesis, granulation tissue formation, and repair of full-thickness skin defects $^{174}$. A recent case study presented by Sun and co-workers showed that the application of a 3D-printed scaffold fabricated with poly(L-lactide acid) (PLLA) and gelatin which are absorbable materials, in combination with PRF, is a highly effective way to repair difficult-to-heal wounds ${ }^{175}$. Interestingly, this kind of system demonstrated ease of application and complete absorption without the need to be removed or changed, two features that increase comfort for patients involved in the study.

\subsubsection{Platelet lysate}

Platelet lysate $(P L)$ is a hemoderivative obtained by platelet destruction through freeze-thawing of a PRP sample in the presence of an anticoagulant. It was shown to recapitulate activities of different cell types involved in wound healing ${ }^{176,177}$. The possibility of using allogeneic PL, minimizes individual variability and therefore represents an advantage compared to patient derivatives such as PRP or PRF. Different controlledrelease systems were developed to provide sustained PL delivery to wounds, including sponge-like dressing ${ }^{178-180}$, mucoadhesive gel ${ }^{181}$, contact lenses ${ }^{182}$, and eye drops ${ }^{183}$. 
Mori and coworkers proposed a powdered alginate dressing for the combined delivery of PL and an antibiotic drug (vancomycin hydrochloride) in chronic skin ulcers ${ }^{184}$. The alginate powder particles, once applied to the wound, were able to absorb wound exudates to form a gel and, simultaneously release the active drugs. In vitro studies showed that the alginate particles were able to modulate the release of two different therapeutic agents and, at the same time, enhanced fibroblast proliferation. As previously mentioned, the combined delivery to skin lesions of multiple actives offers major advantages in wound healing, especially if one of these molecules is an anti-infective drug able to eliminate infections, the most likely single cause of delayed healing. Following this concept, a dressing made of hyaluronic acid particles coated with a calcium alginate shell embedded in an alginate matrix, was proposed for the combined delivery of PL and vancomycin hydrochloride to chronic skin ulcers ${ }^{185}$. A more complex dressing containing silver sulfadiazine as an antiinfective drug, alpha tocopherol as an antioxidant agent, and loaded with autologous PL was proposed by Bonferoni et al. for the treatment of chronic skin wounds ${ }^{186}$.

\subsubsection{Fibrin-based delivery strategies for GFs}

Fibrin is an insoluble macromolecule essential for hemostasis and wound healing, where it plays a major role as a provisional matrix for cells and local reservoir for the sequestration and spatiotemporal release of GFs and cytokines in the wound area ${ }^{187,188 .}$ Fibrin is derived from fibrinogen, a soluble protein produced by the liver and found in blood plasma, by the action of the serine protease thrombin, which is activated by a cascade of enzymatic reactions triggered by vessel wall injury, activated blood cells, or a foreign surface. After injury, the natural fibrin hydrogel (clot) that is created effectively manages hemostasis, and at the same time forming a $3 \mathrm{D}$ matrix for the proliferation and migration of cells into the wounded area. Moreover, fibrin has a selective chemotactic activity for endothelial cells (ECs), and it also has an intrinsic angiogenic activity. The colonization of cells in the fibrin clot is an important event in wound healing as the entrapped cells release a pool of GFs with local activity that drives neovascularization and subsequent remodeling of the wound bed.

The structural and mechanical characteristics, as well as the inherent biological features of fibrin hydrogels, have drawn attention to the potential of this material in the rapidly expanding field of tissue engineering and regenerative medicine. Fibrin-based sealants (fibrin glues), based on fibrinogen/FXIII and thrombin concentrates that form a fibrin hydrogel upon mixing, have been marketed and used for a long time to effectively manage hemostasis and wound healing during surgical interventions. However, more recently, fibrin hydrogels have been further exploited to develop some strategies for delivering therapeutic biomolecules to the wound site ${ }^{189}$.

Fibrin can be used for wound delivery simply by the incorporation of (one or several) therapeutic molecules into a fibrinogen/thrombin formulation, which can be subsequently applied to acute or chronic wounds. Alternatively, fibrin can be tailored into diverse structures such as MPs or NPs, to finely control the release kinetics of the delivered molecule ${ }^{190}$. Both these strategies have turned out to be very promising for the delivery of therapeutic biomolecules, particularly GFs, to sustain their release and protect them from 
rapid deactivation in the hostile wound environment ${ }^{189,} 191$. The GF release profile from a fibrin matrix depends principally on the mechanical properties of the matrix, the fibrinolytic activity in the area of application and the mode of GF interaction with fibrin. Many different approaches have been attempted to alter the release kinetics by either modifying the biophysical properties of the fibrin matrix (such as the amount of cross-linking and the density of the gel) or modifying the substance of interest in such a way as to alter the interaction between the two. A detailed discussion of these strategies was reported by Whelan and co-workers in a review and the reader is referred to this for further information ${ }^{191}$.

The feasibility of fibrin to deliver GFs for the treatment of acute and chronic wounds has been demonstrated by many studies. Initially, the research was focused on the delivery of GFs able to stimulate an angiogenic activity, taking advantage of the ability of fibrin and its degradation products to intrinsically stimulate angiogenesis. Many angiogenic GFs, such as bFGF, PDGF-A, PDGF-B and VEGF ${ }^{165}$ have been incorporated into fibrin matrices and successfully delivered to enhance new vessel formation ${ }^{97,100,192-195}$. Interestingly, the natural affinity of these GFs for fibrin slows down their release from the matrix as they will primarily be released upon cell infiltration and subsequent matrix degradation ${ }^{191}$. At the same time, fibrin hydrogels have also been employed as delivery vehicles for a range of nonangiogenic GFs associated with wound healing such as KGF ${ }^{196,197}$ and EGF ${ }^{198}$.

Despite several attempts and the encouraging pre-clinical data, the clinical translation of fibrin hydrogels is very limited. The main issue is the quick passive diffusion of GFs out of the matrix within the first few hours upon application to the injured site. The rapid fibrin degradation in vivo, and the weak binding of some GFs to fibrin leads to a burst release of GFs, resulting in supra-physiological doses whereas a slower and more controlled release is required to induce optimal therapeutic efficacy. Various approaches have been investigated to alter the release kinetics of GFs from fibrin matrices ${ }^{189}$, including alteration of the composition of the matrix, incorporation of heparin, encapsulation of GFs into micro or nanosystems, and the use of recombinant proteins or bi-domain peptides (synthesized peptides which can be functionalized to bind both fibrin on one end and GF on the other) (Fig. 5).

The different natural binding affinities of GFs or the combination of two or more of these strategies to alter the GFs release from a fibrin matrix can be further exploited to achieve the sequential release of two or more bioactive molecules. For example, Wong and coauthors used the different fibrin affinities of GFs to achieve a sequential release of bFGF (highest fibrin affinity), VEGF 165 (high fibrin affinity) and VEGF 121 (low fibrin affinity), from a biomatrix prepared using fibrin sealant product components ${ }^{199}$. The same concept was applied by Briganti et al. who used heparin to modify the release of VEGF and aFGF ${ }^{200}$ and by Drinnan et al. who used PEGylated fibrin to achieve sequential release of PDGF-BB (entrapped in fibrin) and TGF- $\beta$ (bound to a homobifunctional PEG linker) ${ }^{192}$. Layman et al. reported a sequential bFGF and G-CSF delivery system using GF-loaded albumin microspheres embedded in fibrin ${ }^{201,202}$. The results of all these studies, indicated that the combined sequential release of multiple GFs constituted an improvement over the delivery of individual GFs for enhancing neovascularization in in vivo models.

Finally, the combined delivery of GFs and cells to support tissue formation and 
functionality have been explored, and shown very promising results ${ }^{189,191}$. In this respect, it is worthwhile to mention the works of Mogford et al. who showed beneficial effects of dermal fibroblasts in fibrin gels loaded with PDGF-BB on a rabbit ear cutaneous wound healing model ${ }^{203}$, and Gwak et al. who observed a faster and more pronounced epidermal regeneration in mice when a combination of keratinocytes and EGF in fibrin was sprayed into full-thickness wounds compared to single controls 204 .

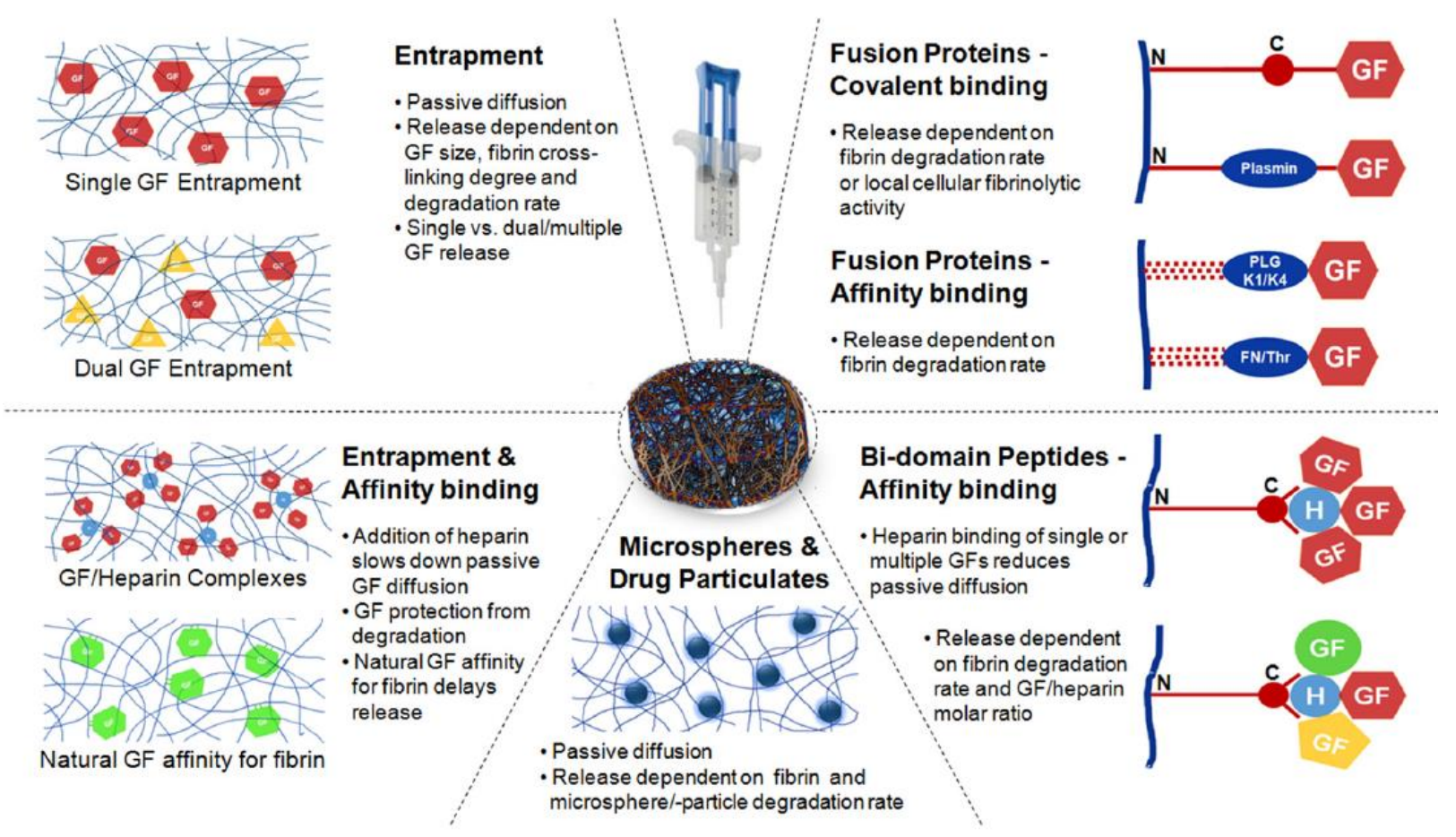

Figure 5. Modes of GF release from fibrin matrices. GFs can be (i) entrapped into fibrin (burst release), (ii) bound via natural affinity or heparin complexation (slower release) or (iii) covalently bound via bi-domain peptide or fusion protein technologies (slowest release). Furthermore, microspheres carrying drugs or GFs can be incorporated into the fibrin matrix for sustained release. GF: growth factor, H: heparin, PLG: plasminogen, K1/4: kringle domain 1/4, FN: fibronectin, Thr: thrombin. Reproduced from Heher et al. ${ }^{189}$ with permission from Elsevier. 


\section{CONCLUSIONS}

Polymeric (synthetic, semisynthetic, or naturally derived) dressings are potentially an ideal delivery platform for integration of single or multiple GFs, making possible controlled delivery in the proximity of the wounded area thus avoiding side effects and exposure of non-target sites. The versatility offered by the different materials used and formulation methods allows the fine control of the delivery of GFs both spatially and temporally, a crucial factor in their effective and safe use as regenerative medicines in clinical practice. The ability to deliver multiple GFs simultaneously to the wound site allows an ideal multitargeted approach to chronic wounds, which are generally not caused by a single factor but involve multiple complications. The advantages of GF-loaded wound dressings are now well established at the laboratory scale or small production suites, but as often happens, their translation into the clinics is still very limited due to the high production costs, difficult storage conditions, and poor stability of biologically active molecules. The incorporation of microand nano-sized particles in wound dressing could be a powerful tool to overcome these shortcomings but additional research should be undertaken to explore increasingly reliable techniques to improve the preparation methods and quality control.

In conclusion, the potential of GF-loaded wound dressings is well-founded, and novel delivery technologies could significantly contribute to improving human health. These products do more than just covering and concealing of the wounds, and can also play an active role in tissue regeneration and remodeling, enhance full regeneration of skin while also reducing the formation or size of the resulting scars. These unique advantages make them appealing platforms for the future treatment of the chronic wounds, an increasingly important and debilitating disease worldwide. 


\section{EXPERT OPINION}

The direct delivery of GFs to chronic wound sites and other difficult to heal wounds, using dressings (either currently on the market or novel designs) is a feasible therapeutic approach that is expected to accelerate wound healing and reduce scar formation especially in patients with a high risk of infections and complications, as is the case for DFUs. Extensive development and innovations are ongoing in the field of medicated dressings, using different polymers, (both natural and synthetic), for effective delivery of GFs supported by the advances in tissue engineered scaffold technologies. The development of scaffolds based on biopolymeric matrices such as collagen and hyaluronic acid, together with the application of advanced and more sophisticated manufacturing technologies such as electrospinning, nanoencapsulation and 3D printing, have significantly enhanced the opportunities for more targeted delivery. In addition, there has been significant interest in blood-derived products such as PRP, PRF, PL, and fibrin, which contain appropriate levels of multiple GFs, driven by the advances in biotechnological techniques comprising bioengineering and biomedical science collaborations, which enable high throughput and industrial scale-up capabilities.

The advantages of incorporating antimicrobials within wound dressings to fight infections typical of a wound site are now well established, even in clinical practice. However, in the case of GF-loaded wound dressings, significant additional barriers and limitations remain that need to be overcome before routine delivery of GFs using dressings can become a reality in clinical practice. These include the poor physical, chemical, and biological stability of GFs to various conditions such as temperature (during formulation and processing), and protease enzymes (within exudate and the wound bed), which makes it difficult to achieve effective therapeutic doses able to trigger efficient and timely wound healing. Another challenge is the need to control the correct spatiotemporal release of the active ingredient from the dressing to mimic the chronological release profiles of GFs that occur in real physiological situations. The complexity of the wound healing process and differences between the types of chronic wounds require a tunable multi-targeted approach, where various biologicals are delivered simultaneously to target different phases of wound healing. For this reason, research in this field has evolved towards a more interdisciplinary approach, involving pharmaceutical technology, clinical physiology and pathology, reconstructive surgery, and biomedical engineering for the development of more sophisticated wound dressings, which take advantage of two or more drug delivery strategies, with the ultimate aim of developing novel therapies applicable in clinical settings. The integration of MPs and NPs into wound dressings could be critical to overcoming the inherent instability of GFs, while simultaneously offering an adequate control over the release rate. Many investigations have led to encouraging outcomes in various in vitro and in vivo wound models, and it is expected that in the future, some of these technologies will satisfy clinical requirements and become commercially available. Other encouraging outcomes have involved the use of 3D printing and 3D bioprinting which have the potential to achieve the accurate spatiotemporal deposition of GFs to achieve more efficient targeted delivery to the wound site. Furthermore, the more gentle processing makes it well suited for preparing medicated dressings comprising single or multiple GFs as is the case for PRP, $\mathrm{PRF}$ and PL as well as enable the embedding of cells that have the potential to produce 
specific GFs without being destroyed during manufacture. In addition, 3D printing can allow the incorporation of chemical and bio-sensors, that could control the delivery of the target GFs at the appropriate stage of the wound healing process. This will enable smart delivery via remote sensing, able to detect when a specific dose of the GF is needed in response to biochemical signals such as $\mathrm{pH}$, temperature, osmolality, ionic strength, and specific enzymes within the wound bed.

Finally, for the clinical application of these types of dressing, we must not underestimate the impact of regulatory barriers and the higher cost of GF-loaded dressing compared to the corresponding plain moist wound dressing. The registration process needed for the commercialization of GF-loaded wound dressings is probably one of the most critical phases in the development of these delivery systems, due in part to the absence of reliable cheap animal wound models. In general, the regulatory approval process is complicated by safety issues, specific storage requirements, and short shelf lives. GFs, either synthesized or extracted from natural sources, are very expensive and therefore likely to increase the unit cost per dressing. However, over the course of treatment to complete healing, the anticipated rapid healing is expected to make it cost-effective overall, compared to standard moist wound dressings. The prospects are therefore still exciting as they present the potential to treat patients' wounds in a more personalized and targeted way, to improve healing outcomes and potentially reduce the duration of healing, hospital stays, as well as significantly reduce complexities such as severe infections, amputations and ultimately fatalities. Overall, this will reduce the costs to patients and health providers, enhance patient quality of life with ultimate economic and social benefit through avoiding indirect costs from loss of working hours and personal income. On the other hand, the safety of these systems is still a major challenge, as the direct and continuous administration of GFs presents potential serious adverse effects including the uncontrolled growth of normal healthy cells when in contact with GFs and therefore an increased risk of tumors and cancers.

Given the constant research in the area of wound healing biomaterials, the improvements in our understanding of skin biology and the physiological processes of wound repair, it is safe to predict that these biological-based, biomaterial-delivered therapies will become prominent in routine wound care management. We believe that in the next 5 to 10 years, GF-loaded dressings will provide a highly tunable treatment for difficult to heal chronic wounds such as DFUs, PUs and leg ulcers where standard therapies have failed. Wound dressings prepared using the new manufacturing technologies, such as 3D printing or bio-electrospraying/spinning, in combination with a well-defined mixture of GFs and/or living cells, will be a cheaper and safer alternative to skin grafts (painful and need to create a fresh wound) and tissue engineered skin substitutes (expensive and require expert health personnel to administer) for the treatment of difficult to heal chronic wounds. Moreover, considering genetic variability, wound type, and the patient's clinical and metabolic features, it will be possible to offer more patient specific and more effective therapies, potentially moving towards an era of personalized clinical care. 


\section{Highlights}

- Polymeric wound dressings and scaffolds have the potential to serve as platforms for delivering growth factors directly to chronic wound sites.

- Direct delivery of growth factors has the potential to shorten the healing time for chronic ulcers and eliminate or significantly reduce scar formation after healing.

- Direct delivery of plain growth factors to wounds still face the challenge of achieving effective therapeutic doses due to dilution by exudate and enzymatic degradation. Therefore, encapsulation using micro-and nano- particles before loading into dressing matrix in the form of a composite system, represent a viable approach to overcome this limitation.

- Blood derived products such as platelet-rich plasma, platelet-rich fibrin and platelet lysate represent an important reservoir to enable delivery of multiple growth factors in a single administration.

- New technologies such as electrospinning and 3D printing represent a novel approach that can overcome the problem of achieving the correct spatiotemporal delivery of growth factors to mimic their physiological performance in vivo.

\section{ACKNOWLEDGMENTS}

Figure 3 was prepared using Servier Medical Art, available from www.servier.com/Powerpoint-image-bank.

\section{DECLARATION OF INTEREST}

The authors have no relevant affiliations or financial involvement with any organization or entity with a financial interest in or financial conflict with the subject matter or materials discussed in the manuscript. This includes employment, consultancies, honoraria, stock ownership or options, expert testimony, grants or patents received or pending, or royalties. 


\section{BIBLIOGRAPHY}

Papers of special note have been highlighted as either of interest $(\bullet)$ or of considerable interest $(\bullet \bullet)$ to readers.

1. Zhao A, Qin H, Fu X. What Determines the Regenerative Capacity in Animals? BioScience 2016;66(9):735-46.

2. lismaa SE, Kaidonis X, Nicks AM, Bogush N, Kikuchi K, Naqvi N, et al. Comparative regenerative mechanisms across different mammalian tissues. NPJ Regenerative medicine 2018;3:6-6.

3. Lorenz HP, Longaker MT, Perkocha LA, Jennings RW, Harrison MR, Adzick NS. Scarless wound repair: a human fetal skin model. Development 1992 Jan;114(1):253-9.

4. Gurtner GC, Werner S, Barrandon Y, Longaker MT. Wound repair and regeneration. Nature 2008 May 15;453(7193):314-21.

5. Eming SA, Martin P, Tomic-Canic M. Wound repair and regeneration: mechanisms, signaling, and translation. Sci Transl Med 2014 Dec 3;6(265):265sr6.

-• This review provides an inside into various aspects of wound healing and its management;

6. Pugliese E, Coentro JQ, Raghunath M, Zeugolis DI. Wound healing and scar wars. Adv Drug Deliv Rev 2018 Apr;129:1-3.

7. Wynn TA. Fibrotic disease and the $T(H) 1 / T(H) 2$ paradigm. Nature Reviews Immunology 2004 Aug;4(8):583-94.

8. Velnar T, Bailey $T$, Smrkolj $\mathrm{V}$. The wound healing process: an overview of the cellular and molecular mechanisms. J Int Med Res 2009 Sep-Oct;37(5):1528-42.

9. Brem H, Tomic-Canic M. Cellular and molecular basis of wound healing in diabetes. J Clin Invest 2007 May;117(5):1219-22.

10. Xue M, Zhao R, Lin H, Jackson C. Delivery systems of current biologicals for the treatment of chronic cutaneous wounds and severe burns. Adv Drug Deliv Rev 2018 Apr;129:219-41.

- Interesting review on the use of drug delivery systems for wound healing applications;

11. Dubay DA, Franz MG. Acute wound healing: the biology of acute wound failure. Surg Clin North Am 2003 Jun;83(3):463-81.

12. Catanzano O, Boateng J. Local Delivery of Growth Factors Using Wound Dressings. Therapeutic Dressings and Wound Healing Applications 2020 2020/03/02:291-314.

13. Lazarus GS, Cooper DM, Knighton DR, Percoraro RE, Rodeheaver G, Robson MC. Definitions and guidelines for assessment of wounds and evaluation of healing. Wound Repair Regen 1994 Jul;2(3):165-70. 
14. Armstrong DG, Boulton AJM, Bus SA. Diabetic Foot Ulcers and Their Recurrence. N Engl J Med 2017 2017/06/15;376(24):2367-75.

15. Zubair M, Ahmad J. Role of growth factors and cytokines in diabetic foot ulcer healing: A detailed review. Rev Endocr Metab Disord 2019 2019/06/01;20(2):207-17.

16. Lindley LE, Stojadinovic O, Pastar I, Tomic-Canic M. Biology and Biomarkers for Wound Healing. Plast Reconstr Surg 2016 Sep;138(3 Suppl):18S-28S.

17. Trengove NJ, Stacey MC, MacAuley S, Bennett N, Gibson J, Burslem F, et al. Analysis of the acute and chronic wound environments: the role of proteases and their inhibitors. Wound Repair Regen 1999 Nov-Dec;7(6):442-52.

18. McCarty SM, Percival SL. Proteases and Delayed Wound Healing. Adv Wound Care (New Rochelle) 2013 Oct;2(8):438-47.

19. Xue M, Le NT, Jackson CJ. Targeting matrix metalloproteases to improve cutaneous wound healing. Expert Opin Ther Targets 2006 Feb;10(1):143-55.

20. Wall IB, Moseley R, Baird DM, Kipling D, Giles P, Laffafian I, et al. Fibroblast dysfunction is a key factor in the non-healing of chronic venous leg ulcers. J Invest Dermatol 2008 Oct;128(10):2526-40.

21. Cook H, Davies KJ, Harding KG, Thomas DW. Defective extracellular matrix reorganization by chronic wound fibroblasts is associated with alterations in TIMP-1, TIMP2, and MMP-2 activity. J Invest Dermatol 2000 Aug;115(2):225-33.

22. Rodriguez-Menocal L, Salgado M, Ford D, Van Badiavas E. Stimulation of skin and wound fibroblast migration by mesenchymal stem cells derived from normal donors and chronic wound patients. Stem Cells Transl Med 2012 Mar;1(3):221-9.

23. Stojadinovic O, Brem H, Vouthounis C, Lee B, Fallon J, Stallcup M, et al. Molecular pathogenesis of chronic wounds: the role of beta-catenin and c-myc in the inhibition of epithelialization and wound healing. Am J Pathol 2005 Jul;167(1):59-69.

24. Kim H, Kim Y, Park J, Hwang NS, Lee YK, Hwang Y. Recent Advances in Engineered Stem Cell-Derived Cell Sheets for Tissue Regeneration. Polymers (Basel) 2019 Jan $26 ; 11(2)$.

25. Ulrich D, Ulrich F, Unglaub F, Piatkowski A, Pallua N. Matrix metalloproteinases and tissue inhibitors of metalloproteinases in patients with different types of scars and keloids. $J$ Plast Reconstr Aesthet Surg 2010 Jun;63(6):1015-21.

26. Xue M, Jackson CJ. Extracellular Matrix Reorganization During Wound Healing and Its Impact on Abnormal Scarring. Adv Wound Care (New Rochelle) 2015 Mar 1;4(3):11936.

27. Cubison TC, Pape SA, Parkhouse N. Evidence for the link between healing time and the development of hypertrophic scars (HTS) in paediatric burns due to scald injury. Burns 2006 Dec;32(8):992-9.

28. Finnerty CC, Jeschke MG, Branski LK, Barret JP, Dziewulski P, Herndon DN. Hypertrophic scarring: the greatest unmet challenge after burn injury. Lancet 2016 Oct 
1;388(10052):1427-36.

29. Zhu Z, Ding J, Tredget EE. The molecular basis of hypertrophic scars. Burns Trauma 2016;4:2.

30. Lian N, Li T. Growth factor pathways in hypertrophic scars: Molecular pathogenesis and therapeutic implications. Biomed Pharmacother 2016 Dec;84:42-50.

31. Vågesjö E, Öhnstedt E, Mortier A, Lofton H, Huss F, Prust P, Roos S, Phillipson M. Accelerated wound healing in mice by on-site production and delivery of CXCL12 by transformed lactic acid bacteria. Proc Nat Acad Sci (PNAS) 2018;115(8):1895-1900.

32. Tripathi S, Soni K, Agrawal P, Gour V, Mondal R, Soni V. Hypertrophic scars and keloids: a review and current treatment modalities. Biomedical Dermatology 2020 2020/05/20;4(1):11.

33. Huang C, Murphy GF, Akaishi S, Ogawa R. Keloids and hypertrophic scars: update and future directions. Plast Reconstr Surg Glob Open 2013 Jul;1(4):e25.

34. Smith CJ, Smith JC, Finn MC. The possible role of mast cells (allergy) in the production of keloid and hypertrophic scarring. J Burn Care Rehabil 1987 Mar-Apr;8(2):12631.

35. Werner S, Grose R. Regulation of wound healing by growth factors and cytokines. Physiol Rev 2003 Jul;83(3):835-70.

36. Kim HS, Sun X, Lee JH, Kim HW, Fu X, Leong KW. Advanced drug delivery systems and artificial skin grafts for skin wound healing. Adv Drug Deliv Rev 2018 Dec 31.

37. Rennert RC, Rodrigues M, Wong VW, Duscher D, Hu M, Maan Z, et al. Biological therapies for the treatment of cutaneous wounds: phase III and launched therapies. Expert Opin Biol Ther 2013 Nov;13(11):1523-41.

38. Leader B, Baca QJ, Golan DE. Protein therapeutics: a summary and pharmacological classification. Nat Rev Drug Discov 2008 Jan;7(1):21-39.

39. Park JW, Hwang SR, Yoon IS. Advanced Growth Factor Delivery Systems in Wound Management and Skin Regeneration. Molecules 2017 Jul 27;22(8).

40. Barrientos S, Brem H, Stojadinovic O, Tomic-Canic M. Clinical application of growth factors and cytokines in wound healing. Wound Repair Regen 2014 Sep-Oct;22(5):569-78.

- Overview of the current clinical application of GFs and cytokines in wound healing;

41. Barrientos S, Stojadinovic O, Golinko MS, Brem H, Tomic-Canic M. Growth factors and cytokines in wound healing. Wound Repair Regen 2008 Sep-Oct;16(5):585-601.

42. Dinh T, Braunagel S, Rosenblum BI. Growth factors in wound healing: the present and the future? Clin Podiatr Med Surg 2015 Jan;32(1):109-19.

43. Falanga V. Chronic Wounds: Pathophysiologic and Experimental Considerations. Journal of Investigative Dermatology 1993 1993/05/01/;100(5):721-25. 
44. Pierce GF, Tarpley JE, Tseng J, Bready J, Chang D, Kenney WC, et al. Detection of platelet-derived growth factor (PDGF)-AA in actively healing human wounds treated with recombinant PDGF-BB and absence of PDGF in chronic nonhealing wounds. J Clin Invest 1995 Sep;96(3):1336-50.

45. Schultz GS, Wysocki A. Interactions between extracellular matrix and growth factors in wound healing. Wound Repair Regen 2009 Mar-Apr;17(2):153-62.

46. Quatresooz P, Henry F, Paquet P, Pierard-Franchimont C, Harding K, Pierard GE. Deciphering the impaired cytokine cascades in chronic leg ulcers (review). Int $\mathrm{J}$ Mol Med 2003 Apr;11(4):411-8.

47. Mast BA, Schultz GS. Interactions of cytokines, growth factors, and proteases in acute and chronic wounds. Wound Repair Regen 1996 Oct;4(4):411-20.

48. Cooper DM, Yu EZ, Hennessey P, Ko F, Robson MC. Determination of endogenous cytokines in chronic wounds. Ann Surg 1994 Jun;219(6):688-91; discussion 91-2.

49. Cianfarani F, Tommasi R, Failla CM, Viviano MT, Annessi G, Papi M, et al. Granulocyte/macrophage colony-stimulating factor treatment of human chronic ulcers promotes angiogenesis associated with de novo vascular endothelial growth factor transcription in the ulcer bed. Br J Dermatol 2006 Jan;154(1):34-41.

50. Berlanga-Acosta J, Fernandez-Montequin J, Valdes-Perez C, Savigne-Gutierrez W, Mendoza-Mari Y, Garcia-Ojalvo A, et al. Diabetic Foot Ulcers and Epidermal Growth Factor: Revisiting the Local Delivery Route for a Successful Outcome. Biomed Res Int 2017;2017:2923759.

51. Gainza G, Villullas S, Pedraz JL, Hernandez RM, Igartua M. Advances in drug delivery systems (DDSs) to release growth factors for wound healing and skin regeneration. Nanomedicine 2015 Aug;11(6):1551-73.

52. Brown GL, Nanney LB, Griffen J, Cramer AB, Yancey JM, Curtsinger LJ, 3rd, et al. Enhancement of wound healing by topical treatment with epidermal growth factor. $\mathrm{N}$ Engl $\mathrm{J}$ Med 1989 Jul 13;321(2):76-9.

53. Fang $\mathrm{RC}$, Galiano RD. A review of becaplermin gel in the treatment of diabetic neuropathic foot ulcers. Biologics 2008 Mar;2(1):1-12.

54. Steed DL. Clinical evaluation of recombinant human platelet-derived growth factor for the treatment of lower extremity diabetic ulcers. Diabetic Ulcer Study Group. J Vasc Surg 1995 Jan;21(1):71-8; discussion 79-81.

55. Wieman TJ, Smiell JM, Su Y. Efficacy and safety of a topical gel formulation of recombinant human platelet-derived growth factor-BB (becaplermin) in patients with chronic neuropathic diabetic ulcers. A phase III randomized placebo-controlled double-blind study. Diabetes Care 1998 May;21(5):822-7.

56. Margolis DJ, Bartus C, Hoffstad O, Malay S, Berlin JA. Effectiveness of recombinant human platelet-derived growth factor for the treatment of diabetic neuropathic foot ulcers. Wound Repair Regen 2005 Nov-Dec;13(6):531-6.

57. Fernandez-Montequin JI, Betancourt BY, Leyva-Gonzalez G, Mola EL, Galan- 
Naranjo K, Ramirez-Navas M, et al. Intralesional administration of epidermal growth factorbased formulation (Heberprot-P) in chronic diabetic foot ulcer: treatment up to complete wound closure. Int Wound J 2009 Feb;6(1):67-72.

58. Smiell JM. Clinical safety of becaplermin (rhPDGF-BB) gel. Becaplermin Studies Group. Am J Surg 1998 Aug;176(2A Suppl):68S-73S.

59. Akita S, Akino K, Imaizumi T, Hirano A. Basic fibroblast growth factor accelerates and improves second-degree burn wound healing. Wound Repair Regen 2008 SepOct;16(5):635-41.

60. Yao CC, Yao P, Wu H, Zha ZG. Acceleration of wound healing in traumatic ulcers by absorbable collagen sponge containing recombinant basic fibroblast growth factor. Biomedical Materials 2006 Mar;1(1):33-37.

61. Tuyet HL, Nguyen Quynh TT, Vo Hoang Minh H, Thi Bich DN, Do Dinh T, Le Tan D, et al. The efficacy and safety of epidermal growth factor in treatment of diabetic foot ulcers: the preliminary results. Int Wound J 2009 Apr;6(2):159-66.

62. Kozynets HP, Osadcha OI, Boiars'ka HM, Tsyhankov VP, Nazarenko VM, Solodkyi Iu A. [Determination of clinical efficacy of REGEN-D 150 preparation for local treatment of burns]. Klin Khir $2011 \mathrm{Jul}(7): 65-8$.

63. Boateng JS, Matthews KH, Stevens HN, Eccleston GM. Wound healing dressings and drug delivery systems: a review. J Pharm Sci 2008 Aug;97(8):2892-923.

64. Boateng J, Catanzano O. Advanced Therapeutic Dressings for Effective Wound Healing--A Review. J Pharm Sci 2015 Nov;104(11):3653-80.

\section{- Exaustive description of advanced dressings for wound healing;}

65. Biondi M, Ungaro F, Quaglia F, Netti PA. Controlled drug delivery in tissue engineering. Adv Drug Deliv Rev 2008 Jan 14;60(2):229-42.

66. Fenton OS, Olafson KN, Pillai PS, Mitchell MJ, Langer R. Advances in Biomaterials for Drug Delivery. Adv Mater 2018 May 7:e1705328.

67. Quaglia F. Bioinspired tissue engineering: the great promise of protein delivery technologies. Int J Pharm 2008 Dec 8;364(2):281-97.

68. Choi SM, Lee KM, Kim HJ, Park IK, Kang HJ, Shin HC, et al. Effects of structurally stabilized EGF and bFGF on wound healing in type I and type II diabetic mice. Acta Biomater 2018 Jan 15;66:325-34.

69. Lao G, Yan L, Yang C, Zhang L, Zhang S, Zhou Y. Controlled release of epidermal growth factor from hydrogels accelerates wound healing in diabetic rats. J Am Podiatr Med Assoc 2012 Mar-Apr;102(2):89-98.

70. Lin YJ, Lee GH, Chou CW, Chen YP, Wu TH, Lin HR. Stimulation of wound healing by $\mathrm{PU} /$ hydrogel composites containing fibroblast growth factor-2. Journal of Materials Chemistry B 2015;3(9):1931-41.

71. Niiyama $\mathrm{H}$, Kuroyanagi $\mathrm{Y}$. Development of novel wound dressing composed of 
hyaluronic acid and collagen sponge containing epidermal growth factor and vitamin C derivative. J Artif Organs 2014 Mar;17(1):81-7.

72. Schneider A, Wang XY, Kaplan DL, Garlick JA, Egles C. Biofunctionalized electrospun silk mats as a topical bioactive dressing for accelerated wound healing. Acta Biomater 2009 Sep;5(7):2570-8.

73. Lord MS, Ellis AL, Farrugia BL, Whitelock JM, Grenett H, Li C, et al. Perlecan and vascular endothelial growth factor-encoding DNA-loaded chitosan scaffolds promote angiogenesis and wound healing. J Control Release 2017 Mar 28;250:48-61.

74. Gilmartin DJ, Soon A, Thrasivoulou C, Phillips AR, Jayasinghe SN, Becker DL. Sustained Release of $\mathrm{Cx} 43$ Antisense Oligodeoxynucleotides from Coated Collagen Scaffolds Promotes Wound Healing. Adv Healthc Mater 2016 Jul;5(14):1786-99.

75. Subbiah R, Guldberg RE. Materials Science and Design Principles of Growth Factor Delivery Systems in Tissue Engineering and Regenerative Medicine. Adv Healthc Mater 2019 2019/01/01;8(1):1801000.

76. Barroso A, Mestre H, Ascenso A, Simões S, Reis C. Nanomaterials in wound healing: From material sciences to wound healing applications. Nano Select 2020 2020/11/01;1(5):443-60.

77. Elsabahy M, Wooley KL. Design of polymeric nanoparticles for biomedical delivery applications. Chem Soc Rev 2012 Apr 7;41(7):2545-61.

78. Beckert S, Farrahi F, Aslam RS, Scheuenstuhl H, Konigsrainer A, Hussain MZ, et al. Lactate stimulates endothelial cell migration. Wound Repair Regen 2006 MayJun;14(3):321-4.

79. Trabold O, Wagner S, Wicke C, Scheuenstuhl H, Hussain MZ, Rosen N, et al. Lactate and oxygen constitute a fundamental regulatory mechanism in wound healing. Wound Repair Regen 2003 2003/11/01;11(6):504-09.

80. Borselli C, Ungaro F, Oliviero O, d'Angelo I, Quaglia F, La Rotonda MI, et al. Bioactivation of collagen matrices through sustained VEGF release from PLGA microspheres. J Biomed Mater Res A 2010 2010/01/01;92A(1):94-102.

81. Matica MA, Aachmann FL, Tondervik A, Sletta H, Ostafe V. Chitosan as a Wound Dressing Starting Material: Antimicrobial Properties and Mode of Action. Int J Mol Sci 2019 Nov 24;20(23).

82. Desmet CM, Preat V, Gallez B. Nanomedicines and gene therapy for the delivery of growth factors to improve perfusion and oxygenation in wound healing. Adv Drug Deliv Rev 2018 Apr;129:262-84.

83. Kalashnikova I, Das S, Seal S. Nanomaterials for wound healing: scope and advancement. Nanomedicine (Lond) 2015;10(16):2593-612.

84. Vijayan A, James PP, Nanditha CK, Kumar GSV. Multiple cargo deliveries of growth factors and antimicrobial peptide using biodegradable nanopolymer as a potential wound healing system. International journal of nanomedicine 2019;14:2253-63. 
85. Tanaka A, Nagate $T$, Matsuda $H$. Acceleration of wound healing by gelatin film dressings with epidermal growth factor. J Vet Med Sci 2005 Sep;67(9):909-13.

86. Yang DH, Seo DI, Lee D-W, Bhang SH, Park K, Jang G, et al. Preparation and evaluation of visible-light cured glycol chitosan hydrogel dressing containing dual growth factors for accelerated wound healing. Journal of Industrial and Engineering Chemistry 2017 2017/09/25/;53:360-70.

87. Shimizu N, Ishida D, Yamamoto A, Kuroyanagi M, Kuroyanagi Y. Development of a functional wound dressing composed of hyaluronic acid spongy sheet containing bioactive components: evaluation of wound healing potential in animal tests. J Biomater Sci Polym Ed 2014;25(12):1278-91.

88. Choi JS, Yoo HS. Pluronic/chitosan hydrogels containing epidermal growth factor with wound-adhesive and photo-crosslinkable properties. J Biomed Mater Res A 2010 Nov;95(2):564-73.

89. Beckert S, Haack S, Hierlemann H, Farrahi F, Mayer P, Konigsrainer A, et al. Stimulation of steroid-suppressed cutaneous healing by repeated topical application of IGFI: different mechanisms of action based upon the mode of IGF-I delivery. J Surg Res 2007 May 15;139(2):217-21.

90. Picheth GF, Sierakowski MR, Woehl MA, Ono L, Cofre AR, Vanin LP, et al. Lysozyme-triggered epidermal growth factor release from bacterial cellulose membranes controlled by smart nanostructured films. J Pharm Sci 2014 Dec;103(12):3958-65.

91. Xuan X, Zhou Y, Chen A, Zheng S, An Y, He H, et al. Silver crosslinked injectable bFGF-eluting supramolecular hydrogels speed up infected wound healing. Journal of Materials Chemistry B 2020 Feb 21;8(7):1359-70.

92. Hong JP, Kim YW, Lee SK, Kim SH, Min KH. The effect of continuous release of recombinant human epidermal growth factor (rh-EGF) in chitosan film on full thickness excisional porcine wounds. Ann Plast Surg 2008 Oct;61(4):457-62.

93. Hu Y, Zhang Z, Li Y, Ding X, Li D, Shen C, et al. Dual-Crosslinked Amorphous Polysaccharide Hydrogels Based on Chitosan/Alginate for Wound Healing Applications. Macromol Rapid Commun 2018 May 31:e1800069.

94. Pyun DG, Choi HJ, Yoon HS, Thambi T, Lee DS. Polyurethane foam containing rhEGF as a dressing material for healing diabetic wounds: Synthesis, characterization, in vitro and in vivo studies. Colloids Surf B Biointerfaces 2015 Nov 1;135:699-706.

95. Wang W, Lin S, Xiao Y, Huang Y, Tan Y, Cai L, et al. Acceleration of diabetic wound healing with chitosan-crosslinked collagen sponge containing recombinant human acidic fibroblast growth factor in healing-impaired STZ diabetic rats. Life Sci 2008 Jan 16;82(34):190-204.

96. Wang $Y$, Fu C, Wu Z, Chen L, Chen X, Wei Y, et al. A chitin film containing basic fibroblast growth factor with a chitin-binding domain as wound dressings. Carbohydr Polym 2017 Oct 15;174:723-30.

97. Losi P, Briganti E, Errico C, Lisella A, Sanguinetti E, Chiellini F, et al. Fibrin-based 
scaffold incorporating VEGF- and bFGF-loaded nanoparticles stimulates wound healing in diabetic mice. Acta Biomater 2013 Aug;9(8):7814-21.

\section{- Interesting example of delivery of two different GFs for a synergic action on wound healing;}

98. Ulubayram K, Nur Cakar A, Korkusuz P, Ertan C, Hasirci N. EGF containing gelatinbased wound dressings. Biomaterials 2001 Jun;22(11):1345-56.

99. Ribeiro MP, Morgado PI, Miguel SP, Coutinho P, Correia IJ. Dextran-based hydrogel containing chitosan microparticles loaded with growth factors to be used in wound healing. Mater Sci Eng C Mater Biol Appl 2013 Jul 1;33(5):2958-66.

100. Mohandas A, Anisha BS, Chennazhi KP, Jayakumar R. Chitosan-hyaluronic acid/VEGF loaded fibrin nanoparticles composite sponges for enhancing angiogenesis in wounds. Colloids Surf B Biointerfaces 2015 Mar 1;127:105-13.

101. Li X, Ye X, Qi J, Fan R, Gao X, Wu Y, et al. EGF and curcumin co-encapsulated nanoparticle/hydrogel system as potent skin regeneration agent. Int $\mathrm{J}$ Nanomedicine 2016;11:3993-4009.

102. Lin X, Guan X, Wu Y, Zhuang S, Wu Y, Du L, et al. An alginate/poly(Nisopropylacrylamide)-based composite hydrogel dressing with stepwise delivery of drug and growth factor for wound repair. Materials Science and Engineering: C 2020 2020/10/01/;115:111123.

103. Hajimiri M, Shahverdi S, Esfandiari MA, Larijani B, Atyabi F, Rajabiani A, et al. Preparation of hydrogel embedded polymer-growth factor conjugated nanoparticles as a diabetic wound dressing. Drug Development and Industrial Pharmacy 2016 May 3;42(5):707-19.

104. Piran M, Vakilian S, Piran M, Mohammadi-Sangcheshmeh A, Hosseinzadeh S, Ardeshirylajimi A. In vitro fibroblast migration by sustained release of PDGF-BB loaded in chitosan nanoparticles incorporated in electrospun nanofibers for wound dressing applications. Artificial Cells, Nanomedicine, and Biotechnology 2018 2018/10/31;46(sup1):511-20.

105. Nejaddehbashi F, Hashemitabar M, Bayati V, Abbaspour M, Moghimipour E, Orazizadeh M. Application of polycaprolactone, chitosan, and collagen composite as a nanofibrous mat loaded with silver sulfadiazine and growth factors for wound dressing. Artif Organs 2019 Apr;43(4):413-23.

106. Liao AH, Hung CR, Chen HK, Chiang CP. Ultrasound-Mediated EGF-CoatedMicrobubble Cavitation in Dressings for Wound-Healing Applications. Sci Rep 2018 May 29;8(1):8327.

107. Wu J, Ye J, Zhu J, Xiao Z, He C, Shi H, et al. Heparin-Based Coacervate of FGF2 Improves Dermal Regeneration by Asserting a Synergistic Role with Cell Proliferation and Endogenous Facilitated VEGF for Cutaneous Wound Healing. Biomacromolecules 2016 Jun 13;17(6):2168-77.

108. He S, Shi D, Han Z, Dong Z, Xie Y, Zhang F, et al. Heparinized silk fibroin hydrogels 
loading FGF1 promote the wound healing in rats with full-thickness skin excision. Biomed Eng Online 2019 Oct 2;18(1):97.

109. Vijayan A, A S, Kumar GSV. PEG grafted chitosan scaffold for dual growth factor delivery for enhanced wound healing. Sci Rep 2019 Dec 16;9(1):19165.

110. Sakamoto M, Morimoto N, Ogino S, Jinno C, Taira T, Suzuki S. Efficacy of gelatin gel sheets in sustaining the release of basic fibroblast growth factor for murine skin defects. J Surg Res 2016 Apr;201(2):378-87.

111. Etxabide A, Vairo C, Santos-Vizcaino E, Guerrero P, Pedraz JL, Igartua M, et al. Ultra thin hydro-films based on lactose-crosslinked fish gelatin for wound healing applications. Int J Pharm 2017 Sep 15;530(1-2):455-67.

112. Oh JS, Lee EJ. Engineered dressing of hybrid chitosan-silica for effective delivery of keratin growth factor and acceleration of wound healing. Mater Sci Eng C Mater Biol Appl 2019 Oct;103:109815.

113. Sokolsky-Papkov M, Agashi K, Olaye A, Shakesheff K, Domb AJ. Polymer carriers for drug delivery in tissue engineering. Adv Drug Delliv Rev 2007 2007/05/30/;59(4):187206.

114. Shi M, Zhang H, Song T, Liu X, Gao Y, Zhou J, et al. Sustainable Dual Release of Antibiotic and Growth Factor from $\mathrm{pH}$-Responsive Uniform Alginate Composite Microparticles to Enhance Wound Healing. ACS Appl Mater Interfaces 2019 Jun $26 ; 11(25): 22730-44$.

115. Kim H, Kong WH, Seong KY, Sung DK, Jeong H, Kim JK, et al. HyaluronateEpidermal Growth Factor Conjugate for Skin Wound Healing and Regeneration. Biomacromolecules 2016 Nov 14;17(11):3694-705.

116. Silva AKA, Richard C, Bessodes M, Scherman D, Merten O-W. Growth Factor Delivery Approaches in Hydrogels. Biomacromolecules 2009 2009/01/12;10(1):9-18.

117. Niu Y, Li Q, Ding Y, Dong L, Wang C. Engineered delivery strategies for enhanced control of growth factor activities in wound healing. Adv Drug Deliv Rev 2019 Jun;146:190208.

118. Xie Z, Paras CB, Weng H, Punnakitikashem P, Su LC, Vu K, et al. Dual growth factor releasing multi-functional nanofibers for wound healing. Acta Biomater 2013 Dec;9(12):9351-9.

119. Jazwa A, Kucharzewska P, Leja J, Zagorska A, Sierpniowska A, Stepniewski J, et al. Combined vascular endothelial growth factor-A and fibroblast growth factor 4 gene transfer improves wound healing in diabetic mice. Genet Vaccines Ther 2010;8:6.

120. Yancopoulos GD, Davis S, Gale NW, Rudge JS, Wiegand SJ, Holash J. Vascularspecific growth factors and blood vessel formation. Nature 2000 Sep 14;407(6801):242-8.

121. Choi DH, Subbiah R, Kim IH, Han DK, Park K. Dual growth factor delivery using biocompatible core-shell microcapsules for angiogenesis. Small 2013;9(20):3468-76.

122. Gizaw M, Thompson J, Faglie A, Lee SY, Neuenschwander P, Chou SF. Electrospun 
Fibers as a Dressing Material for Drug and Biological Agent Delivery in Wound Healing Applications. Bioengineering (Basel) 2018 Jan 27;5(1).

123. Zamani M, Prabhakaran MP, Ramakrishna S. Advances in drug delivery via electrospun and electrosprayed nanomaterials. Int J Nanomedicine 2013;8:2997-3017.

124. Miguel SP, Sequeira RS, Moreira AF, Cabral CSD, Mendonca AG, Ferreira P, et al. An overview of electrospun membranes loaded with bioactive molecules for improving the wound healing process. Eur J Pharm Biopharm 2019 Jun;139:1-22.

125. Meinel AJ, Germershaus O, Luhmann T, Merkle HP, Meinel L. Electrospun matrices for localized drug delivery: Current technologies and selected biomedical applications. European Journal of Pharmaceutics and Biopharmaceutics 2012 2012/05/01/;81(1):1-13.

\section{- Exellent overview on the use of electrospun matrices for wound application;}

126. Son YJ, Kim WJ, Yoo HS. Therapeutic applications of electrospun nanofibers for drug delivery systems. Arch Pharm Res 2014 Jan;37(1):69-78.

127. Chen S, Liu B, Carlson MA, Gombart AF, Reilly DA, Xie J. Recent advances in electrospun nanofibers for wound healing. Nanomedicine (Lond) 2017 Jun;12(11):1335-52.

128. Liu M, Duan XP, Li YM, Yang DP, Long YZ. Electrospun nanofibers for wound healing. Mater Sci Eng C Mater Biol Appl 2017 Jul 1;76:1413-23.

129. Sebe I, Szabo P, Kallai-Szabo B, Zelko R. Incorporating small molecules or biologics into nanofibers for optimized drug release: A review. Int J Pharm 2015 Oct 15;494(1):51630 .

130. Choi JS, Leong KW, Yoo HS. In vivo wound healing of diabetic ulcers using electrospun nanofibers immobilized with human epidermal growth factor (EGF). Biomaterials 2008 Feb;29(5):587-96.

131. Dwivedi C, Pandey I, Pandey H, Patil S, Mishra SB, Pandey AC, et al. In vivo diabetic wound healing with nanofibrous scaffolds modified with gentamicin and recombinant human epidermal growth factor. J Biomed Mater Res A 2018 Mar;106(3):641-51.

\section{- This paper describes the dual delivery of an antibiotic and a GF;}

132. Jiang $\mathrm{H}$, Wang $\mathrm{L}$, Zhu K. Coaxial electrospinning for encapsulation and controlled release of fragile water-soluble bioactive agents. J Control Release 2014 Nov 10;193:296303.

133. Ji W, Yang F, van den Beucken JJ, Bian Z, Fan M, Chen Z, et al. Fibrous scaffolds loaded with protein prepared by blend or coaxial electrospinning. Acta Biomater 2010 Nov;6(11):4199-207.

134. Choi JS, Choi SH, Yoo HS. Coaxial electrospun nanofibers for treatment of diabetic ulcers with binary release of multiple growth factors. J Mater Chem 2011;21(14):5258-67.

135. Lai HJ, Kuan CH, Wu HC, Tsai JC, Chen TM, Hsieh DJ, et al. Tailored design of electrospun composite nanofibers with staged release of multiple angiogenic growth factors for chronic wound healing. Acta Biomater 2014 Oct;10(10):4156-66. 
136. McClellan P, Landis WJ. Recent Applications of Coaxial and Emulsion Electrospinning Methods in the Field of Tissue Engineering. Biores Open Access 2016;5(1):212-27.

137. Zhang $\mathrm{C}$, Feng $\mathrm{F}$, Zhang $\mathrm{H}$. Emulsion electrospinning: Fundamentals, food applications and prospects. Trends Food Sci Tech 2018 2018/10/01/;80:175-86.

138. Yang Y, Xia T, Zhi W, Wei L, Weng J, Zhang C, et al. Promotion of skin regeneration in diabetic rats by electrospun core-sheath fibers loaded with basic fibroblast growth factor. Biomaterials 2011 Jun;32(18):4243-54.

139. Garcia-Orue I, Gainza G, Gutierrez FB, Aguirre JJ, Evora C, Pedraz JL, et al. Novel nanofibrous dressings containing rhEGF and Aloe vera for wound healing applications. Int J Pharm 2017 May 25;523(2):556-66.

140. Norouzi M, Shabani I, Ahvaz HH, Soleimani M. PLGA/gelatin hybrid nanofibrous scaffolds encapsulating EGF for skin regeneration. J Biomed Mater Res A 2014 Oct 24.

141. Wang Z, Qian Y, Li L, Pan L, Njunge LW, Dong L, et al. Evaluation of emulsion electrospun polycaprolactone/hyaluronan/epidermal growth factor nanofibrous scaffolds for wound healing. J Biomater Appl 2016 Jan;30(6):686-98.

142. Zhao Q, Lu WW, Wang M. Modulating the release of vascular endothelial growth factor by negative-voltage emulsion electrospinning for improved vascular regeneration. Materials Letters 2017 2017/04/15/;193:1-4.

143. Mouthuy PA, Groszkowski L, Ye H. Performances of a portable electrospinning apparatus. Biotechnol Lett 2015 May;37(5):1107-16.

144. Xu SC, Qin CC, Yu M, Dong RH, Yan X, Zhao H, et al. A battery-operated portable handheld electrospinning apparatus. Nanoscale 2015 Aug 7;7(29):12351-5.

145. Yan X, Yu M, Zhang LH, Jia XS, Li JT, Duan XP, et al. A portable electrospinning apparatus based on a small solar cell and a hand generator: design, performance and application. Nanoscale 2016 Jan 7;8(1):209-13.

146. Brown TD, Dalton PD, Hutmacher DW. Direct writing by way of melt electrospinning. Adv Mater 2011 Dec 15;23(47):5651-7.

147. Ristovski N, Bock N, Liao S, Powell SK, Ren J, Kirby GT, et al. Improved fabrication of melt electrospun tissue engineering scaffolds using direct writing and advanced electric field control. Biointerphases 2015 Mar 25;10(1):011006.

148. Kim G, Son J, Park Su A, Kim W. Hybrid Process for Fabricating 3D Hierarchical Scaffolds Combining Rapid Prototyping and Electrospinning. Macromol Rapid Commun 2008 2008/10/01;29(19):1577-81.

149. Ross R, Glomset J, Kariya B, Harker L. A platelet-dependent serum factor that stimulates the proliferation of arterial smooth muscle cells in vitro. Proc Natl Acad Sci U S A 1974 Apr;71(4):1207-10.

150. Mazzucco L, Borzini P, Gope R. Platelet-derived factors involved in tissue repair-from signal to function. Transfus Med Rev 2010 Jul;24(3):218-34. 
151. Bhanot S, Alex JC. Current applications of platelet gels in facial plastic surgery. Facial Plast Surg 2002;18(1):27-33.

\section{-. This review provides an inside into various aspects of the applications of platelet in wound management.}

152. Foster TE, Puskas BL, Mandelbaum BR, Gerhardt MB, Rodeo SA. Platelet-rich plasma: from basic science to clinical applications. Am J Sports Med 2009 Nov;37(11):225972.

153. Saucedo JM, Yaffe MA, Berschback JC, Hsu WK, Kalainov DM. Platelet-rich plasma. J Hand Surg Am 2012 Mar;37(3):587-9; quiz 90.

154. Chicharro-Alcantara D, Rubio-Zaragoza M, Damia-Gimenez E, Carrillo-Poveda JM, Cuervo-Serrato B, Pelaez-Gorrea P, et al. Platelet Rich Plasma: New Insights for Cutaneous Wound Healing Management. J Funct Biomater 2018 Jan 18;9(1).

155. Eppley BL, Woodell JE, Higgins J. Platelet quantification and growth factor analysis from platelet-rich plasma: implications for wound healing. Plast Reconstr Surg 2004 Nov;114(6):1502-8.

156. Roukis TS, Zgonis T, Tiernan B. Autologous platelet-rich plasma for wound and osseous healing: a review of the literature and commercially available products. Adv Ther 2006 Mar-Apr;23(2):218-37.

157. Bir SC, Esaki J, Marui A, Yamahara K, Tsubota H, Ikeda T, et al. Angiogenic properties of sustained release platelet-rich plasma: characterization in-vitro and in the ischemic hind limb of the mouse. J Vasc Surg 2009 Oct;50(4):870-79 e2.

158. Mendes BB, Gomez-Florit M, Babo PS, Domingues RM, Reis RL, Gomes ME. Blood derivatives awaken in regenerative medicine strategies to modulate wound healing. Adv Drug Deliv Rev 2018 Apr;129:376-93.

159. Marx RE. Platelet-rich plasma: evidence to support its use. J Oral Maxillofac Surg 2004 Apr;62(4):489-96.

160. Naik B, Karunakar P, Jayadev M, Marshal VR. Role of Platelet rich fibrin in wound healing: A critical review. J Conserv Dent 2013 Jul;16(4):284-93.

161. Dougherty EJ. An evidence-based model comparing the cost-effectiveness of platelet-rich plasma gel to alternative therapies for patients with nonhealing diabetic foot ulcers. Adv Skin Wound Care 2008 Dec;21(12):568-75.

162. Tsai HC, Lehman CW, Chen CM. Use of platelet-rich plasma and platelet-derived patches to treat chronic wounds. J Wound Care 2019 Jan 2;28(1):15-21.

163. Mazzocca AD, McCarthy MB, Chowaniec DM, Cote MP, Romeo AA, Bradley JP, et al. Platelet-rich plasma differs according to preparation method and human variability. $J$ Bone Joint Surg Am 2012 Feb 15;94(4):308-16.

164. Patel S, Dhillon MS, Aggarwal S, Marwaha N, Jain A. Treatment with platelet-rich plasma is more effective than placebo for knee osteoarthritis: a prospective, double-blind, randomized trial. Am J Sports Med 2013 Feb;41(2):356-64. 
165. Sam G, Vadakkekuttical RJ, Amol NV. In vitro evaluation of mechanical properties of platelet-rich fibrin membrane and scanning electron microscopic examination of its surface characteristics. J Indian Soc Periodontol 2015 Jan-Feb;19(1):32-6.

166. Qiu M, Chen D, Shen C, Shen J, Zhao H, He Y. Platelet-Rich Plasma-Loaded Poly(d,I-lactide)-Poly(ethylene glycol)-Poly(d,I-lactide) Hydrogel Dressing Promotes FullThickness Skin Wound Healing in a Rodent Model. Int J Mol Sci 2016 Jun 24;17(7).

167. Mohammadi R, Mehrtash M, Mehrtash M, Hassani N, Hassanpour A. Effect of Platelet Rich Plasma Combined with Chitosan Biodegradable Film on Full-Thickness Wound Healing in Rat Model. Bull Emerg Trauma 2016 Jan;4(1):29-37.

168. Kim W, Jang $\mathrm{CH}$, Kim G. Optimally designed collagen/polycaprolactone biocomposites supplemented with controlled release of HA/TCP/rhBMP-2 and HA/TCP/PRP for hard tissue regeneration. Mater Sci Eng C Mater Biol Appl 2017 Sep 1;78:763-72.

169. Liu J, Nie H, Xu Z, Guo F, Guo S, Yin J, et al. Construction of PRP-containing nanofibrous scaffolds for controlled release and their application to cartilage regeneration. Journal of Materials Chemistry B 2015;3(4):581-91.

170. Lei X, Yang Y, Shan G, Pan Y, Cheng B. Preparation of ADM/PRP freeze-dried dressing and effect of mice full-thickness skin defect model. Biomedical Materials 2019 Mar 7;14(3):035004.

171. Liu X, Yang Y, Niu X, Lin Q, Zhao B, Wang Y, et al. An in situ photocrosslinkable platelet rich plasma - Complexed hydrogel glue with growth factor controlled release ability to promote cartilage defect repair. Acta Biomater 2017 Oct 15;62:179-87.

172. Notodihardjo PV, Morimoto N, Kakudo N, Matsui M, Sakamoto M, Liem PH, et al. Gelatin hydrogel impregnated with platelet-rich plasma releasate promotes angiogenesis and wound healing in murine model. J Artif Organs 2014 Oct 18.

173. Toffler M, Toscano N, Holtzclaw D, Corso MD, Ehrenfest DD. Introducing Choukroun's platelet rich fibrin (PRF) to the reconstructive surgery milieu. J Implant Adv Clin Dent 2009;1(6):21-30.

174. Suzuki S, Morimoto N, Ikada Y. Gelatin gel as a carrier of platelet-derived growth factors. J Biomater Appl 2013 Nov;28(4):595-606.

175. Sun H, Lv H, Qiu F, Sun D, Gao Y, Chen N, et al. Clinical application of a 3D-printed scaffold in chronic wound treatment: a case series. J Wound Care 2018 May 2;27(5):26271.

176. Barsotti MC, Losi P, Briganti E, Sanguinetti E, Magera A, Al Kayal T, et al. Effect of platelet lysate on human cells involved in different phases of wound healing. PLoS One 2013;8(12):e84753.

177. Ranzato E, Patrone M, Mazzucco L, Burlando B. Platelet lysate stimulates wound repair of HaCaT keratinocytes. Br J Dermatol 2008 Sep;159(3):537-45.

178. Rossi S, Faccendini A, Bonferoni MC, Ferrari F, Sandri G, Del Fante C, et al. "Sponge-like" dressings based on biopolymers for the delivery of platelet lysate to skin chronic wounds. Int J Pharm 2013 Jan 20;440(2):207-15. 
179. Mori M, Rossi S, Ferrari F, Bonferoni MC, Sandri G, Riva F, et al. Sponge-Like Dressings Based on the Association of Chitosan and Sericin for the Treatment of Chronic Skin Ulcers. II. Loading of the Hemoderivative Platelet Lysate. J Pharm Sci 2016 Mar;105(3):1188-95.

180. Nardini M, Perteghella S, Mastracci L, Grillo F, Marrubini G, Bari E, et al. Growth Factors Delivery System for Skin Regeneration: An Advanced Wound Dressing. Pharmaceutics 2020 Feb 3;12(2).

181. Sandri G, Bonferoni MC, Rossi S, Ferrari F, Mori M, Del Fante C, et al. Platelet lysate formulations based on mucoadhesive polymers for the treatment of corneal lesions. J Pharm Pharmacol 2011 Feb;63(2):189-98.

182. Sandri G, Bonferoni MC, Rossi S, Delfino A, Riva F, Icaro Cornaglia A, et al. Platelet lysate and chondroitin sulfate loaded contact lenses to heal corneal lesions. Int $\mathrm{J}$ Pharm 2016 Jul 25;509(1-2):188-96.

183. Sandri G, Bonferoni MC, Rossi S, Ferrari F, Mori M, Del Fante C, et al. Thermosensitive eyedrops containing platelet lysate for the treatment of corneal ulcers. Int J Pharm 2012 Apr 15;426(1-2):1-6.

184. Mori M, Rossi S, Bonferoni MC, Ferrari F, Sandri G, Riva F, et al. Calcium alginate particles for the combined delivery of platelet lysate and vancomycin hydrochloride in chronic skin ulcers. Int J Pharm 2014 Jan 30;461(1-2):505-13.

185. Rossi S, Mori M, Vigani B, Bonferoni MC, Sandri G, Riva F, et al. A novel dressing for the combined delivery of platelet lysate and vancomycin hydrochloride to chronic skin ulcers: Hyaluronic acid particles in alginate matrices. Eur J Pharm Sci 2018 Jun 15;118:8795.

186. Bonferoni MC, Sandri G, Rossi S, Dellera E, Invernizzi A, Boselli C, et al. Association of Alpha Tocopherol and Ag Sulfadiazine Chitosan Oleate Nanocarriers in Bioactive Dressings Supporting Platelet Lysate Application to Skin Wounds. Mar Drugs 2018 Feb 9;16(2).

187. Laurens N, Koolwijk P, de Maat MP. Fibrin structure and wound healing. J Thromb Haemost 2006 May;4(5):932-9.

188. Weisel JW, Litvinov RI. Fibrin Formation, Structure and Properties. Subcell Biochem 2017;82:405-56.

189. Heher P, Muhleder S, Mittermayr R, Redl H, Slezak P. Fibrin-based delivery strategies for acute and chronic wound healing. Adv Drug Deliv Rev 2018 Apr;129:134-47.

190. Rajangam T, An SS. Fibrinogen and fibrin based micro and nano scaffolds incorporated with drugs, proteins, cells and genes for therapeutic biomedical applications. Int J Nanomedicine 2013;8:3641-62.

191. Whelan D, Caplice NM, Clover AJ. Fibrin as a delivery system in wound healing tissue engineering applications. J Control Release 2014 Dec 28;196:1-8.

192. Drinnan CT, Zhang G, Alexander MA, Pulido AS, Suggs LJ. Multimodal release of transforming growth factor-beta1 and the BB isoform of platelet derived growth factor from 
PEGylated fibrin gels. J Control Release 2010 Oct 15;147(2):180-6.

193. Ehrbar M, Djonov VG, Schnell C, Tschanz SA, Martiny-Baron G, Schenk U, et al. Cell-demanded liberation of VEGF121 from fibrin implants induces local and controlled blood vessel growth. Circ Res 2004 Apr 30;94(8):1124-32.

194. Martino MM, Hubbell JA. The 12th-14th type III repeats of fibronectin function as a highly promiscuous growth factor-binding domain. FASEB J 2010 Dec;24(12):4711-21.

195. Pandit AS, Feldman DS, Caulfield J, Thompson A. Stimulation of angiogenesis by FGF-1 delivered through a modified fibrin scaffold. Growth Factors 1998;15(2):113-23.

196. Geer DJ, Swartz DD, Andreadis ST. Biomimetic delivery of keratinocyte growth factor upon cellular demand for accelerated wound healing in vitro and in vivo. Am J Pathol 2005 Dec;167(6):1575-86.

197. Muhamed I, Sproul EP, Ligler FS, Brown AC. Fibrin Nanoparticles Coupled with Keratinocyte Growth Factor Enhance the Dermal Wound-Healing Rate. ACS Appl Mater Interfaces 2019 Jan 30;11(4):3771-80.

198. Zhou W, Zhao M, Zhao Y, Mou Y. A fibrin gel loaded with chitosan nanoparticles for local delivery of rhEGF: preparation and in vitro release studies. J Mater Sci Mater Med 2011 May;22(5):1221-30.

199. Wong C, Inman E, Spaethe R, Helgerson S. Fibrin-based biomaterials to deliver human growth factors. Thromb Haemost 2003 Mar;89(3):573-82.

200. Briganti E, Spiller D, Mirtelli C, Kull S, Counoupas C, Losi P, et al. A composite fibrinbased scaffold for controlled delivery of bioactive pro-angiogenetic growth factors. J Control Release 2010 Feb 25;142(1):14-21.

201. Layman H, Li X, Nagar E, Vial X, Pham SM, Andreopoulos FM. Enhanced angiogenic efficacy through controlled and sustained delivery of FGF-2 and G-CSF from fibrin hydrogels containing ionic-albumin microspheres. J Biomater Sci Polym Ed 2012;23(1-4):185-206.

202. Layman H, Rahnemai-Azar AA, Pham SM, Tsechpenakis G, Andreopoulos FM. Synergistic angiogenic effect of codelivering fibroblast growth factor 2 and granulocytecolony stimulating factor from fibrin scaffolds and bone marrow transplantation in critical limb ischemia. Tissue Eng Part A 2011 Jan;17(1-2):243-54.

203. Mogford JE, Tawil B, Jia S, Mustoe TA. Fibrin sealant combined with fibroblasts and platelet-derived growth factor enhance wound healing in excisional wounds. Wound Repair Regen 2009 May-Jun;17(3):405-10.

204. Gwak SJ, Kim SS, Sung K, Han J, Choi CY, Kim BS. Synergistic effect of keratinocyte transplantation and epidermal growth factor delivery on epidermal regeneration. Cell Transplant 2005;14(10):809-17. 